\title{
XX. Über die Auflösung von Chlornatriumkrystallen in harnstoffhaltigen Lösungen.
}

\author{
Von
}

\author{
Walter Schnorr in Kiel.
}

(Hierzu Tafel $X$ und 20 Textfiguren.)

Inbaltsübersioht.

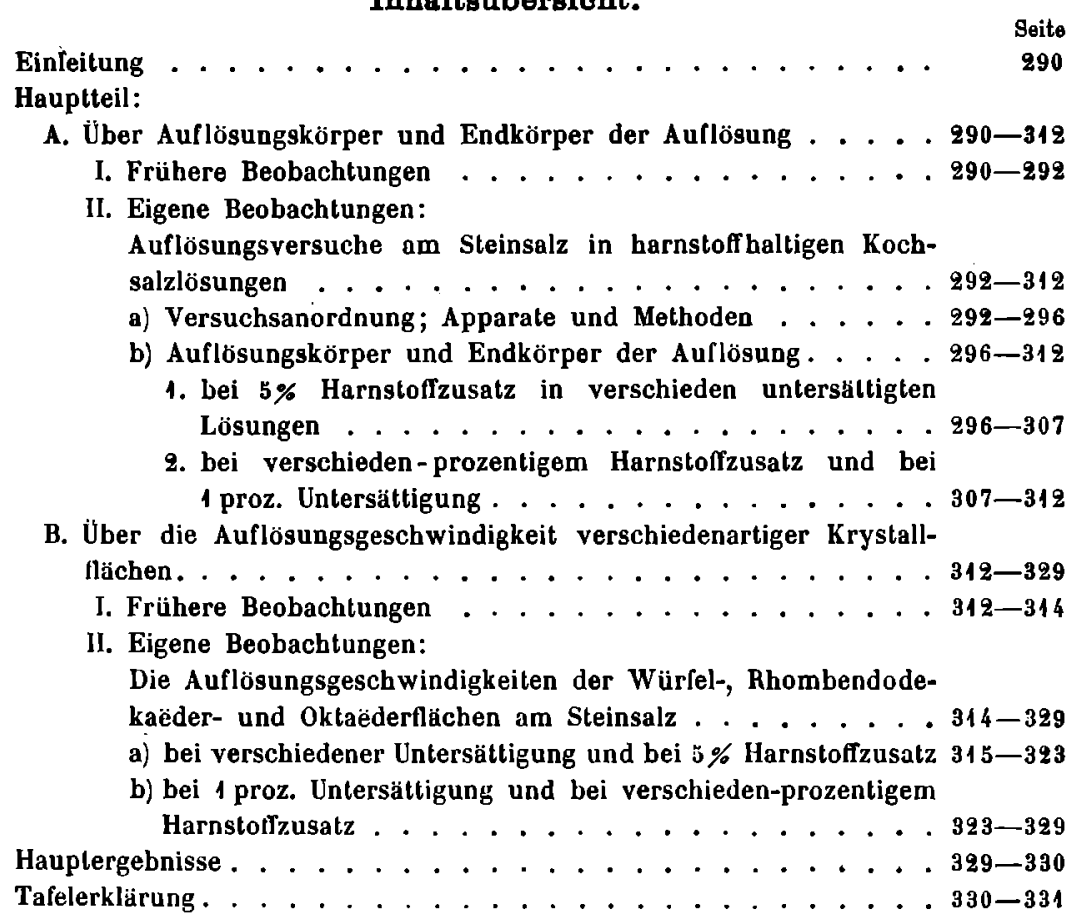




\section{Einloitung.}

In seiner Abhandlung über Wachstum und Auflösung hat A. Johnsen 1 ) die Grundlage zu einer Theorie gegeben, »die jeder Eigentümlichkeit der Krystallauflösung eine solche des Krystallwachstums zuordnet, und alles aus einem einzigen Prinzip herleitet. Es ist das Prinzip des Urpunktes und der virtuellen Flächen $\approx$. Es seien hier die dieser Theorie zugrundeliegenden Begriffe erläutert.

Der Punkt, in dem das Wachstum eines Krystalles beginnt oder die Auflösung eines Krystalles endet, heißt der sUrpunkt des Wachstums a bzw. der > Urpunkt der Auflösung ๔. Jeder Krystallkörper, der in seine untersättigte Lösung gebracht wird, durchläuft eine Reihe von >Auflösungskörpern ^ und geht schließlich in den "Endkörper der Auflösung* über.

Ebenen, die an irgendeinem Krystallkörper auftreten, werden als $\gg$ reelle Flächen «, alle übrigen, die den Krystallkörper in seinen Kanten und Ecken tangierend gedacht werden können, als svirtuelle Flächen « bezeichnet. Auflösungsgeschwindigkeit einer Fläche bedeutet die Normalengeschwindigkeit ihrer Parallelverschiebung. Jede Flächenart hat unter bestimmten Bedingungen eine bestimmte, von ihrer Größe und Umgrenzung unabbängige Verschiebungsgeschwindigkeit.

Die vorliegenden Untersuchungen beziehen sich auf die Auflösungserscheinungen an Chlornatriumkrystallen in harnstoffhaltigen untersättigten Kochsalzlösungen. Es sollten die bei der Auflüsung sich bildenden Auflösungskörper beobachtet und der Einfluß des Harnstoffes geprüft werden. Ferner waren die Auflösungsgeschwindigkeiten verschiedener Flächenarten am Steinsalz zu messen und zu vergleichen.

\section{A. Über Auflösungskörper nnd Endkörper der Auflösung.}

\section{Frühere Beobachtungen.}

Die ālteste Beobachtung über Auflösungserscheinungen finden wir bei Daniell 2) (1816) und bei $\mathrm{Mohs}^{3}$ ) (1824). Eingehendere Versuche über Auflösungskörper sind in neuerer Zeit von A. Johnsent) am Steinsalz gemacht worden. Würfelförmige Ausgangskörper lieferten bei 4 proz. Untersättigung das bloße Ikositetraëder, bei 7 proz. Untersättigung eine Kombination von Ikositetraëder und Rhombendodekaëder als Endkörper der Auflüsung. Kugelförmige Ausgangskörper ergaben bei gleicher Untersättigung

1) A. Johnsen, Wachstum und Auflösung der Krystalle, Leipzig 1910; Ref. diese Zeitschr. 58, 295.

2) Daniell, Journ. of science and the arts, London 1816, 1, 24; referiert nach Leonbard, Taschenbuch für Mineralogie usw. 1818, 549.

3) Mohs, Grundriß der Mineralogie 1824, $8,47$.

4) A. Johnsen, l. c. 13. 
Ubber die Auflösung von Chlornatriumkrystallen in harnstoffbaltigen Lösungen. 291

ăhnliche Endkörper der Auflösung. Auflösungsversuche mit Kugeln geben nach A. Johnsen den besten Aufschluß darüber, welche Flächen die absolut größte Auflösungsgeschwindigkeit besitzen. Eine Kugel wird von unendlich vielen virtuellen Flächen tangiert, die sämtlich die gleiche Urpunktsdistanz haben. Unterwirft man daher eine Kugel der Auflösung, so treten alle diese Flächen die Wanderung nach dem Urpunkt an «. Hierbei werden offenbar die Flächen mit der größten Auflüsungsgeschwindigkeit die geringste Urpunktsdistanz, die Flächen mit kleinerer Auflösungsgeschwindigkeit aber größere Urpunktsdistanzen erhalten. Schnellere Flächen werden weniger schnelle verdrängen, sodaß schließlich ein Endkörper der Auflösung resultiert, der nur von Flächen mit absolut größter Auflösungsgeschwindigkeit umgeben ist.

Auflösungsversuche an Kugeln sind auch früher mehrfach ausgeführt worden. Als erster untersuchte wohl Lavizzari1) kugelförmige Ausgangskörper. Seine Versuche am Kalkspat setzte 0 . Meyer ${ }^{2}$ ) fort. Ferner nahmen 0. Meyer und S. L. Penfield ${ }^{3}$ ), sowie Gill ${ }^{4}$ ) Auflösungsversuche an Quarzkugeln vor. Die eingehendsten Versuche über Auflüsungskürper aus Kugeln sind wohl von Goldschmidt und seinen Schülern ausgeführt worden. Goldschmidt und Wrights) setzten Calcitkugeln der Einwirkung verschiedener Säuren aus. Nach Goldschmidt entstehen beim Angriff des Lüsungsmiltels auf die Kugeloberfläche im Ort der Hauptflächen und im Verlauf der Hauptzonenlinien Ätzgrübchen. Bei weiterem Auflösen bilden sich Ecken an Stelle der Ilauptknoten, scharfe Kanten an Stelle der Hauptzonenlinien. Endlich erreicht der Auflüsungskörper eine von Ecken, Kanten und krummen Flächen begrenzte Geslalt, die sich beim Weiterlösen geometrisch ähnlich, bleibt, während nach Johnsen ${ }^{6}$ ) der Endkörper der Auflösung z. B. eines triklinen Krystalles seine Form bei weitcrer Auflösung dauernd verändern kann. Dic von Goldschmidt aufgestellten Gesetzmäßigkeiten bestätigten $\mathrm{Ph}$. Hochschild ${ }^{7}$ ) an der Zinkblende, V. Rošick ${ }^{8}$ ) an japanischem Tupas und H. Bauhans') am Kalialaun.

1) Lavizzari, Nouveaux phénomenes des corps cristallisés, Lugano 1865.

2) O. Meyer, N. Jahrl). f. Min. 1883, 1, 74; Hef. diesc Zeitschr. 1884, 9, 203.

3) O. Meyer und S. L. Penfield, Trans. Conneclicut Acad. 1889, 8, 157; Ref. diese Zeitschr. 1891, 19, 637.

4) Gill, diese Zeitschr. 1894, 22, 110.

5) V. Goldschmidt und Fr. E. Wrighl, N. Jahrb. f. Min. 1903, Beil.-Bd. 17, 355; Ref. diese Zeilschr. 1906, 41, 521; N. Jahrb. f. Min. 1904, Beil.-Bd. 18, 335; Mef. diese Zeitschr. 1907, 42, 641. Ferner V. Goldschmidt, diese Zeitschr. 1904, 38, 273 und 656; V. Goldschmidt, diese Zeitschr. 1912, 50, 459.

6) Johnsen, 1. c. 22.

7) Ph. Hochschild, N. Jahrb. I. Min. 1908, Beil.-Bd. 26, 151 ; Ref. diese Zeilschr. $1911,49,256$.

8) V. Rošicky, Bübm. Akademie 18, 1909.

9) H. Bauhans, Verhandl. d. Heidelberg. Naturhistorisch-Med. Vereins. Neue Folge, 1913, 12, 319. 
Es sei ferner auf die Arbeit von Mügge ${ }^{1}$ ) über >die Zersetzungsgeschwindigkeit des Quarzes gegenüber Flußsăure verwiesen. Mügge hält es für möglich, $d a ß$ eine hinreichend große Kugel bei hinreichend lange fortgesetzter Ätzung zu einem ringförmigen Körper werden würde, der an der Innen- wie der Außenseite wesentlich von Flächen der Säulenzone begrenzt wird s.

\section{Eigene Beobachtungen.}

Auflösungsversuche am Steinsalz in harnstoffhaltigen Kochsalzlösungen.

a) Versuchsanordnung; Apparate und Methoden.

Die Chlornatriumlösung wurde durch Auflösen von chemisch reinem Chlornatrium (Marke Ph. G. IV von Kahlbaum) in heißem destilliertem Wasser hergestelit. $\quad 100 \mathrm{~cm}^{3} \mathrm{H}_{2} \mathrm{O}$ vermögen bei einer Temperatur von $30^{\circ} \mathrm{C} 36,03 \mathrm{~g}$ $\mathrm{NaCl}$ zu lösen 2), was $26,486 \mathrm{~g} \mathrm{NaCl}$ in $100 \mathrm{~g}$ gesâttigter Lösung und $31,6 \breve{\mathrm{g} ~} \mathrm{NaCl}$ in $100 \mathrm{~cm}^{3}$ gesättigter Lösung entspricht, wenn man deren Dichte $=1,1949$ setzt. Die so hergestellte Lösung wurde filtriert, 12 Liter davon in einen zylindrischen Thermostaten (nach 0stwald) von $28 \mathrm{~cm}$ Höhe und $28 \mathrm{~cm}$ Durchmesser gebracht und bei einer Temperatur von $30^{\circ} \mathrm{C}\left( \pm 0,1^{\circ}\right)$ mittelst eines Toluol-Quecksilberregulators konstant gehalten. Eine ungefähr $2 \mathrm{~cm}$ dicke Schicht von reinem Paraffinöl über der Lösung genügte, um die Verdunstung zu verhindern. Die ständige Bewegung der Lösung bewirkte ein Rührer aus Glas, dessen Flügel sich ungefähr in $10 \mathrm{~cm}$ Abstand vom Boden des Gefäßes befanden. Form und Tourenzahl des Rührers wurden so gewählt, daß dieser die Lösung genügend durchrührte, ohne sie mit der Ölschicht zu vermengen. Der $\mathrm{NaCl}$-Gehalt der Lösung wurde durch Ermittlung des Chlorfaktors mittelst der bekannten Methode im Gooch-Tiegel bestimmt. Die Übersåttigung oder Untersättigung glich ich durch Hinzufügen der berechneten Menge Wasser bzw. Chlornatrium wieder aus. Dieser nunmehr bei $30^{\circ} \mathrm{G}$ gesăttigten Chlornatriumlösung wurde ein bestimmter Harnstoffgehalt gegeben.

Meine Untersuchungen beziehen sich auf harnstoffhaltige Kochsalzlüsungen von $5,10,20,40,60$ und $80 \%$ Harnstoffzusatz (H.Z.). Unter einer Kochsalzlüsung mit $x \%$ Harnstoffzusatz verstehe ich eine Lüsung, die man erhält, wenn man $100 \mathrm{~cm}^{3}$ reine gesättigte Chlornatriumlösung mit $x$ Grammen Harnstoff versetzt.

Das System Harnstoff-Chlornatrium.

Harnstoffzusatz zu einer reinen Chlornatriumlüsung bewirkt eine Lüslichkeitsvergrößerung (L.V.) des $\mathrm{NaCl}$. Diese Löslichkeitsvergrößerung ist

1) O. Mügge, Rosenbusch Festschrift 1906, 96.

2) Landolt'-Börnstein, Tabellen 1905, 556. 
Über die Auflösung von Chlornatriumkrystallen in harnstoffhaltigen Lösungen. 293

von C. Fastert') gemessen und berechnet worden. Tabelle I zeigt die von l'astert gefundenen Werte für die Löslichkeitsvergrößerung bis $40 \%$ H.Z. Die mit einem Stern bezeichneten Werte sind von mir nach der von F astert aufgestellten Formel berechnet worden. Als maximalen Harnstoffzusatz fand ich rund $80 \%$.

Tabelle I.

\begin{tabular}{r|c|c}
\hline H.7. in \% & \multicolumn{2}{|c}{$\begin{array}{c}\text { L.V. in g pro } 100 \mathrm{~cm}^{3} \\
\text { gesättigter } \mathrm{NaCl} \text {-Lösung } \\
\text { gefunden }\end{array}$} \\
\hline 5 & 0,044 & 0,042 \\
10 & 0,124 & 0,126 \\
20 & 0,372 & 0,378 \\
40 & 1,134 & 1,134 \\
60 & - & $2,156^{*}$ \\
80 & - & $3,402^{*}$
\end{tabular}

Diese Werte für die Löslichkeitsvergrößerung benutzte ich bei meinen Lösungen, um eine gesättigte Kochsalzlösung mit $x \%$ Harnstoffzusatz herzustellen. Zur Kontrolle dieser Lösungen wurde ein genügend großer Steinsalzkrystall in die Lösung gebracht, um einen etwaigen Gewichtsverlust durch Auflösung festzustellen. Sobald die Sättigung erreicht war, wurde die Lösung um einen bestimmten Grad untersättigt, wobei ich mit Johnsen unter einer um $n \%$ untersättigten Lösung eine solche verstehe, die man erhält, wenn man zu $(100-n) \mathrm{cm}^{3}$ gesättigter Lösung $n \mathrm{~cm}^{3}$ Lösungsmittel hinzusetzt oder eine Lösung; die $\frac{100-n}{100}$ soviel gelöst enthält wie ein gleiches Volumen gesättigter Lösung.

Die Vorversuche ergahen, daß eine Untersättigung von $1 \%$ und weniger am besten die Auflösungserscheinungen durch Ausbildung von scharfen Kanten und Ecken erkennen ließ.

Um das Volumen einer harnstoffhaltigen und an $\mathrm{NaCl}$ gesättigten Lösung von bekannter Zusammensetzung und bekanntem Gewicht zu erfahren, ermittelte ich die spez. Gewichte dieser Lösungen mittelst der Mohrschen Wage. Aus den nun gegebenen Werten lassen sich die Faktoren (Wasser, Chlornatrium, Harnstoff) der Lösung leicht berechnen. Diese Faktoren waren insofern von Wichtigkeit, als die Lösung stets konstant bleiben sollte, d, h. jede Mehraufnahme an $\mathrm{NaCl}$ durch den Auflösungsprozeß mußte jederzeit durch einen bestimmten Harnstoff- und Wasserzusatz ausgeglichen werden. Tabelle II zeigt diese Werte für an $\mathrm{NaCl}$ bei $30^{\circ} \mathrm{C}$ gesätligte harnstofThaltige Lösungen, welche aus $100 \mathrm{~cm}^{3}$ reiner gesättigter $\mathrm{NaCl}$ Lösung durch Zusatz von Harnstoff und von $\mathrm{NaCl}$ dargestellt sind.

1) C. Fastert, N. Jahrb. f. Min. 1912, Beil.-Bd. 33, 282. 
Tabelle II.

\begin{tabular}{|c|c|c|c|c|c|}
\hline $\mathrm{H} .-\mathrm{Z}$. in $\%$ & Chlornatrium & Wasser & \multicolumn{2}{|c|}{$\begin{array}{c}\text { spez. Gewicht } \\
\text { (Mittel aus } 15 \text { Messungen) }\end{array}$} & Volumen \\
\hline 0 & $31,650 \mathrm{~g}$ & $87,84 \mathrm{~g}$ & \multicolumn{2}{|c|}{$1,1949 \pm 0,000-$} & $100,00 \mathrm{~cm}^{3}$ \\
\hline 5 & 31,692 & , & 1,2028 & 3 & 103,70 \\
\hline 10 & 31,776 & , & 1,2068 & $>2$ & 107,41 \\
\hline 20 & 32,028 & 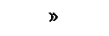 & 1,2143 & $>1$ & 115,18 \\
\hline 40 & 32,784 & , & 1,2263 & $>5$ & 131,01 \\
\hline 60 & 33,806 & , & 1,2347 & $>4$ & 147,12 \\
\hline 80 & 35,052 & , & 1,2434 & $>3$ & 163,19 \\
\hline
\end{tabular}

Ich ging bei meinen Auflüsungsversuchen von 121 reiner gesättigter $\mathrm{NaCl}$-Lösung aus und erhielt also bei verschiedenem Harnstoffzusatz Volumina, die sich aus den Zahlen der letzten Kolonne von Tabelle II ergeben, wenn man dieselben mit 120 multipliziert. Bei einer an $\mathrm{NaCl}$ gesättigten Lösung mit $60 \%$ Harnstoffzusatz ergibt sich dann bereits ein Volumen von 17 $654 \mathrm{~cm}^{3}$, welches der Thermostat nicht mehr fassen konnte. Aus diesem Grunde sind die Auflösungsversuche mit 60 und $80 \%$ Harnstoffzusatz in Lösungen angestellt, welche aus nur 61 reiner gesättigter Chlornatriumlösung durch Zusatz von Harnstoff und von Chlornatrium gewonnen waren. Der Auflösungsprozeß der Steinsalzkörper vollzog sich daher in diesen zwei Lüsungen viel langsamer als in den anderen.

\section{Herstellung der Ausgangskörper.}

Als Material wurden Steinsalzspaltungsstücke von Leopoldshall bei Staßfurt benutzt. Es wurde nur reines Material mit spiegelglatten Spaltflächen verwendet. Als Schleifmittel diente erst feiner Schmirgel und darauf Steinsalzpulver in öl. Hierbei wurden die Flächen oft so glatt und glänzend, daß sich ein nachträgliches Polieren der Flächen als unnötig erwies. Wenn eine Politur erforderlich war, so wurde diese mittelst caput mortuum auf einer mit feinem Leder überspannten Platte vorgenommen. Das Anschleifen der Flächen erfolgte mittelst des von Wülfing ${ }^{1)}$ konstruierten Schleifapparates. Die Lage der Flächen war so bis auf 3-10' genau.

Die würfelfürmigen Ausgangskörper wurden entweder müglichst modellartig herausgespalten oder angeschliffen und poliert. Die Kantenlänge der Steinsalzwürfel wurde $\mathrm{zu} 15-25 \mathrm{~mm}$ groß gewählt. Als zweiten Ausgangskörper stellte ich mir eine Kombination von Rhombendodekaëder und Würfel her. Es wurden nur die Rhombendodekaëderflächen einer Zone, die um $90^{\circ}$ gegeneinander geneigt sind, angeschliffen, sodaß der Ausgangskörper aus vier Rhombendodekaëder- und zwei Würfelflächen bestand. Die zwei Würfelflächen wurden soweit angeschliffen, daß der Ausgangskörper einem

1) Wülfing, N. Jahrb. f. Min. 1901, \&, 1. Ref. diese Zeitschr. 37, 207. 
geometrischen Würfel glich. Für einen einzigen Fall fertigte ich mir ein modellartiges Rhombendodekaëder an. Größere Übung erforderte die Herstellung einer Kombination von Oktaëder und Würfel. Hier wurden sämtliche acht Oktaëderflächen angeschliffen und zwar so, daß nur Kombinationskanten von Würfel- und Oktaëderflächen vorhanden waren.

Ferner benutzte ich als Ausgangskörper Kugeln, die aus großen Spaltungsstücken von Steinsalz in dem hiesigen mineralogischen Institut hergestellt wurden. Einem möglichst modellartigen Spaltungswürfel gab ich zuerst durch Abstumpfung der Kanten und Ecken eine annähernde Kugelgestalt. Dieser Körper wurde dann in einer kugelschaligen Vertiefung, die in einer Platte aus hartem Holz angebracht war, mit Schmirgel und Öl durch Drehen mit der Hand solange geschliffen, bis die Gestalt einer Kugel mit fast glatter Oberfläche erreicht war. Die Durchmesser wurden stets mit einer Schubleere geprüft. Sobald diese nicht mehr als um 3- o\% .voneinander abwichen, wurde das Drehen in der kugelschaligen Vertiefung einer Korkplatte mit feinstem Schmirgel und endlich mit Steinsalzpulver und öl fortgesetzt, bis die Unterschiede der Durchmesser weniger als 1\% betrugen. Die Politur wurde auf einem Lederläppchen vorgenommen, das in die kugelschalige Vertiefung einer Korkplatte gedrückt war. Die Durchmesser der Kugeln waren etwa $20-35 \mathrm{~mm}$ groß.

Die so erhaltenen Ausgangskörper wurden mittelst Kanadabalsam auf die Platte eines kleinen Glasknopfes aufgekiltet, der seinerseits auf einem kleinen Rührer befestigt war. Dadurch wurde es erreicht, daß der Krystallkörper auch auf der unteren Fläche wenigstens teilweise, auf den übrigen Flächen aber vollkommen von dem Lösungsmittel angegriffen werden konnte. Die Methode des kleinen Rührers, der nicht mit dem Hauptrührer des Thermostaten identisch ist, wurde zuerst von A. Johnsen im Jahre 1910 bei seinen Auflüsungsversuchen angewendet und kürzlich von W. Poppe ${ }^{1}$ ) beschrieben.

Die Umdrehungszahl des großen Flügelrades wurde möglichst konstant auf 120-135 Umdrehungen pro Minute gehalten, wāhrend das kleine Flügelrädchen mit dem Krystall in derselben Zeit eine Umdrehungszahl von 40-50 Umdrehungen zeigte.

Bevor die Krystallkörper in die Lösung gebracht wurden, tauchte ich sie in eine gesättigte Chlornatriumlösung und darauf schnell in die Lösung selbst ein. Durch die adhärierende Schicht gesättigter Chlornatriumlösung wurde bewirkt, daß sich keine Partikelchen der die Lösung bedeckenden Ölschicht an den Krystallflächen festsetzten und so an irgendeiner Stelle den

1) W. Poppe, Dissertation Kiel 1914 , Über die Auflösung von Natriumchloridund von Natriumchloratkrystalleñ. 
Auflösungsvorgang beeinträchtigten. Nach dem Herausnehmen aus der Lösung wurden die Krystalle mit Alkohol abgespült und von ihrer Unterlage durch Äther gelöst.

\section{b) Auflösungskörper und Endkörper der Auflösung}

\section{1. bei $5 \%$ Harnstoffzusatz in verschieden untersättigten}

\section{Lösungen.}

Die Untersuchungen über Auflösungskörper bei gleichbleibendem Harnstoffzusatz, aber verschiedener Untersättigung wurden in einer Kochsalzlösung mit $5 \%$ Harnstoffzusatz unternommen. Die Versuche erstrecken sich auf Untersättigungen von $0,25,0,5,1,2$ und $4 \%$. Die Beobachtungen seien im folgenden so geordnet, daß die in Kapitel a) genannten Ausgangskörper in ihrem Verhalten zu den verschiedenen Untersättigungen gesondert betrachtet werden.

\section{Ausgangskörper $\{100\}$.}

Die würfelförmigen Ausgangskörper (Fig. 1 und Taf. X, Fig. 1) wurden stets mit einer ihrer Flächen auf die Platte des Glasknopfes aufgekittet;

Fig. 1.

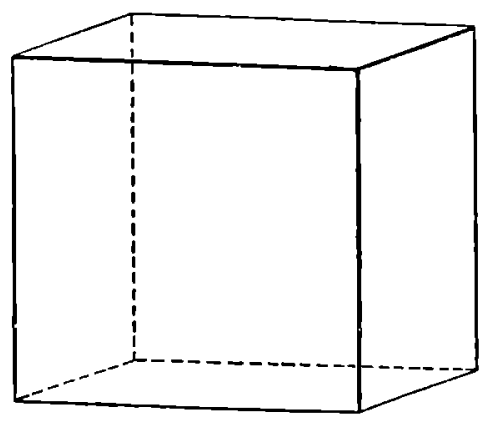

Fig. 2.

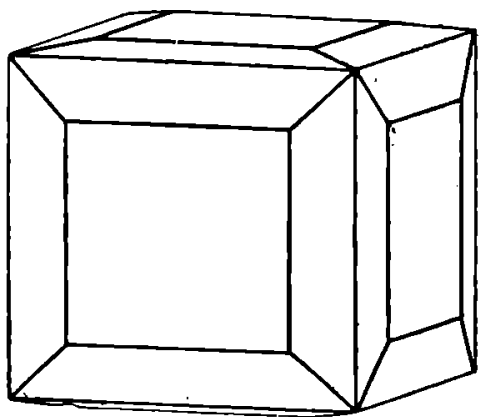

das Aufkitten auf eine angeschliffene Oktaëderfläche erwies sich nicht als vorteilhaft, da in diesem Falle die Auflösungskörper verzerrt erschienen und die Winkelmessungen dadurch erschwert wurden.

Betrachten wir nun die Auflösungsstadien eines Würfels, der in einer um $0,25 \%$ untersättigten Kochsalzlösung mit $5 \%$ Harnstoflzusatz der Auflösung unterworfen wurde. Als Auflösungsflächen entstehen zuerst an den Kanten die 24 Flăchen eines dem Würfel benachbarten Pyramidenwürfels $\{h k 0\}$. (Fig. 2 und Taf. X, Fig. 2.) Diese vergrößern sich bei weiterer Auflösung auf Kosten der Würfelfächen, bis sie diese in das virtuelle Reich zurückgedrängt haben; es resultieren am Auflösungsköroer die 24 Flächen eines Pyramidenwürfels mit scharf ausgebildeten Kanten und Ecken, aber 
Über die Aufösung von Chlornatriumkrystallen in harnstofthaltigen Lösungen. 297

einseitig nach den Würfelkanten gekrümmten Flächen (Fig. 3 und Taf. X, Fig. 3). Nun beginnen an den Ecken sich die 24 Flächen eines Ikositetraëders $\{h k k\}$ aus ihrer virtuellen Lage gegen den Urpunkt hin vorzuschieben. Diese Ikositetraëderflächen liegen nicht in den Zonen $[h \bar{k} 0]$ des

Fig. 3.

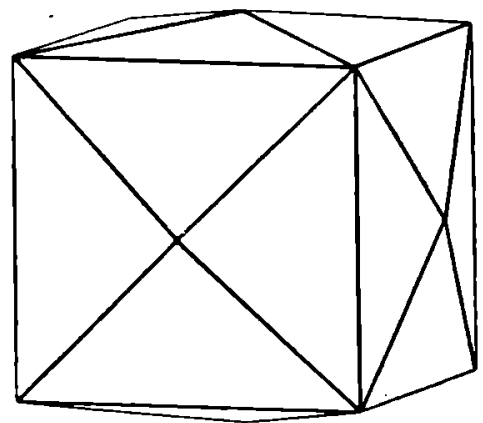

Fig. 4.

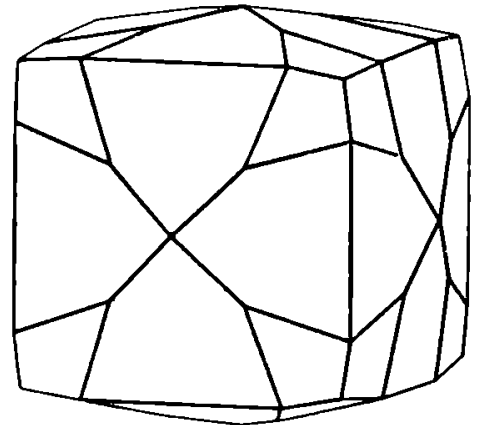

Pyramidenwürfels $\{h k 0\}$. (Fig. 4 und Taf. X, Fig. 4.) Die reell gewordenen Pyramidenwürfelflächen werden nun von den Ikositetraëderflächen allmählich wieder in das virtuelle Reich zurückgedrängt, sodaß sich ein bloßes Ikositetraëder mit scharfen Kanten und Ecken, aber doppelt gekrümmten

Fig. 5.

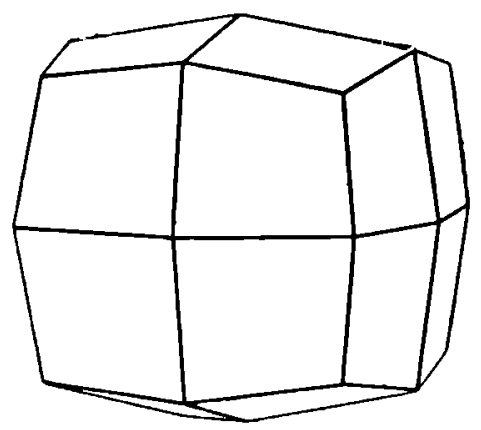

Fig. 6.

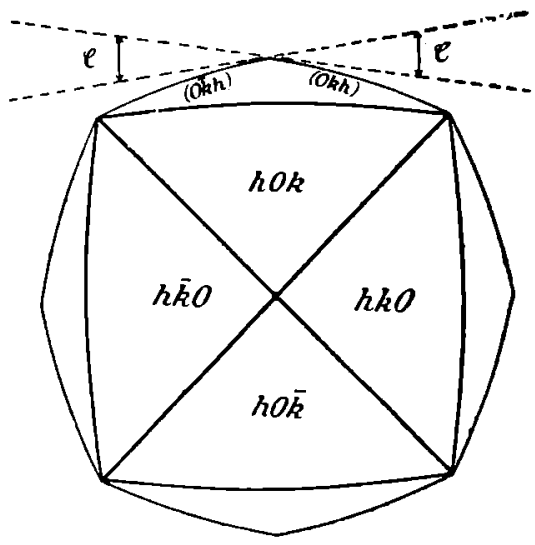

Flächen ergibt (Fig. 5 und Taf. X, Fig. 5). Dieses Ikositetraëder bleibt sich bei weiterer Auflösung vollkommen ähnlich, der Endkörper der Auflösung ist erreicht.

Die Versuche bei $0,5,1,2$ und $4 \%$ Untersättigung ergaben ähnliche Auflösungskörper. Allen gemeinsam ist das Auftreten des gut ausgebildeten 
Pyramidenwürfels. Nur im Endkörper zeigen sich Unterschiede. Bei 2\% und $4 \%$ Untersättigung sind die zweizähligen Ecken des Ikositetraëders verrundet, die Kanten der dreizäbligen Ecken gekrümmt, aber scharf. Hier bildeten sich oft starke Verzerrungen, während die Auflösungskörper bei geringerer Untersättigung fast ein modellartiges Aussehen zeigten. Deutlicher treten die Unterschiede der Endkörper, die aus verschieden untersättigten Lösungen erhalten wurden, bei einem Vergleich der Neigungswinkel der Flächen hervor:

Die Winkelmessungen am Reflexionsgoniometer erfolgten derart, daß beim Pyramidenwürfel die Neigung $(h k 0) \widehat{(h \mid}(\vec{k})$, beim lkositetraëder die Neigung $(h k \hat{k} \widehat{(h \bar{k}} \bar{k})$ ermittelt wurde. Die Winkel in den Tabellen beziehen sich auf diejenigen Partien der gekrümmten $\{h k 0\}$ und $\{h k k\}$, die dem Würfel am nächsten liegen (Fig. 6), da nur diese Flächenteile genauere Messungen gestatteten.

Man kann die Krümmung der Pyramidenwürfelflächen als eine große Anzahl zueinander vizinaler Pyramidenwürfelflächen auffassen. Bei den Messungen ergab sich, daß die Neigung der $\{h k 0\}$ gegen $\{100\}$ bei fortschreitender Auflösung zunahm (Tabelle III und IV). Diese Erscheinung liegt anscheinend in der verschiedenen Verschiebungsgeschwindigkeit der verschiedenen Pyramidenwürfelflächen begründet. Die stärker geneigten $\{h k 0\}$ besitzen eine etwas größere Auflösungsgeschwindigkeit als weniger geneigte. Im Verlauf der Auflösung drängen daher erstere die letzteren wieder in das virtuelle Reich zurück. Andererseits könnte man eine Erklärung darin finden, daß eine minimale Abnahme der Untersättigung infolge des Auflüsungsprozesses eine steilere Neigung der Flächen bewirkt. Versuche, wobei der Krystallkörper von Stunde zu Stunde herausgenommen, gewogen und die Abgabe von $\mathrm{NaCl}$ an die Lösung durch Hinzufügen von Harnstoff und Wasser wieder ausgeglichen wurde, ergaben jedoch die gleiche Erscheinung. Die Zunahme der Neigungswinkel geht bei jeder Untersättigung nur bis zu einem bestimmten Grade und hört gewöhnlich auf, wenn die Ikositetraëderflächen reell werden.

Die Messung der Neigungswinkel der Ikositetraëderflächen ließ sich, solange die Pyramidenwürfelflächen noch vorhanden waren, nicht bewerkstelligen, da die Reflexe der $\{h k k\}$ stets von den Reflexzügen der $\{h k 0\}$ überdeckt wurden. Sobald das bloße Ikositetraëder entstanden war, blieb die Neigung seiner Flächen unter konstanten Bedingungen konstant, d. h. die Flächen des Ikositetraëders verschoben sich nun parallel, der Körper behielt seine geometrische Form. Mit steigender Untersättigung nimmt die Neigung der dem Würfel benachbarten $\{h l c 0\}$ und der $\{h k k\}$ gegenüber dem Würfel allmählich ab. (Vgl. Tabelle V und VI.) 
Über dle Auflösung von Chlornatriumkrystallen in harnstoffhaltigen Lösungen. 299

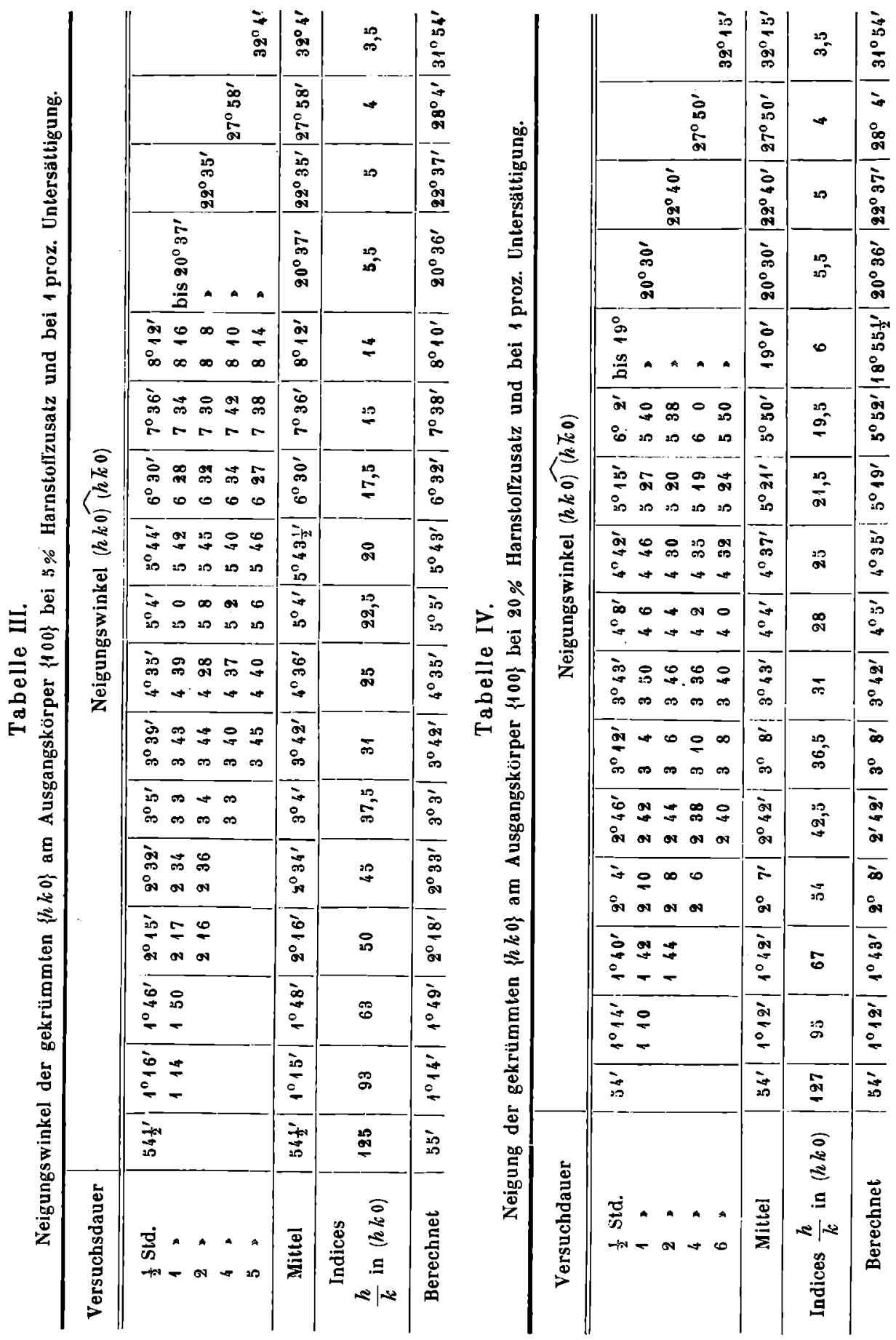




\section{Tabelle V.}

$(h k 0) \widehat{(h k 0)}$ bei $5 \%$ Harnstoflzusatz und bei verschiedenen Untersättigungsgraden. Untersättigung:

Gemessen:

$0,25 \%$
0,5
1
2
4

$4^{\circ} 30^{\prime}-5^{\circ} 36^{\prime}$

$$
3 \quad 42-4 \quad 24
$$

$238-3 \quad 47$

$156-252$

$148-217$

Mittelwert:

Indices:

Berechnet: $5^{\circ} 6^{\prime}$

22.1.0

$5^{\circ} 12^{\prime}$

355

29.1 .0

357

256

39.1 .0

256

224

48.1 .0

223

157

59.1 .0

$156 \frac{1}{2}$

Tabelle VI.

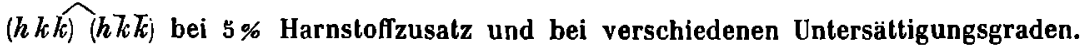

\begin{tabular}{|c|c|c|c|c|}
\hline Untersättigung: & Gemessen: & Mittelwert: & Indices: & rechnet: \\
\hline $0,25 \%$ & $10^{\circ} 28^{\prime}-11^{\circ} 23^{\prime}$ & $10^{\circ} 50^{\prime}$ & 15.1 .1 & $10^{\circ} 481^{\prime}$ \\
\hline 0,5 & $9-1023$ & 948 & 16.1.1 & 10 \\
\hline 1 & $750-855$ & 818 & 19.1.1 & 831 \\
\hline 2 & $520-734$ & 644 & 24.1 .1 & $644 \frac{1}{2}$ \\
\hline 4 & $243-344$ & 318 & 49.1 .1 & 318 \\
\hline
\end{tabular}

Bei dem Übergang von $\{h k 0\}$ in $\{h k k\}$ zeigten sich einige Male, namentlich bei geringerer Untersättigung, auf den Pyramidenwürfelflächen feine, nach den vierzähligen Ecken hin gegeneinander konvergierende Streifcn (Fig. 7). Die Streifung war makroskopisch schwach, unter der Lupe aber

Fig. 7.

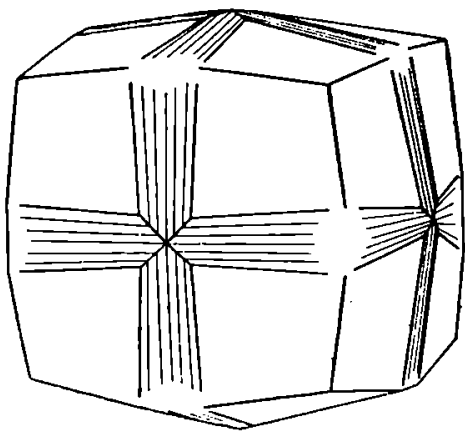

Fig. 8.

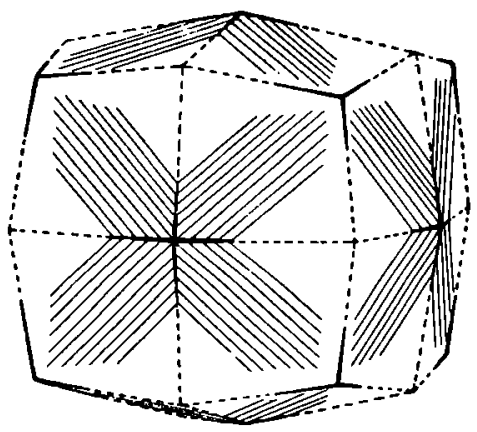

deutlich wahrnehmbar; es ließen sich jedoch keine Messungen vornehmen. Ich fasse diese Streifung als Kombinationsstreifung zwischen den verschiedenen $\{h k 0\}$ und $\{h k k\}$ auf. Bei weiterer Auflösung wurde diese Streifung immer mehr durch die größer werdenden Ikositetraëderflächen zurūckgedrängt, bis letztere schließlich in einer Kante miteinander kombinierten.

Sobald das bloße Ikositetraëder entstanden war, bildeten sich oft auf den Ikositetraëderflächen feine Streifen parallel den Höhenlinien (Fig. 8). Diese Streifung blieb jedoch ebenso wie das Ikositetraëder erhalten, nur wurden die zweizähligen Ecken des Ikositetraëders etwas verrundet. 


$$
\text { Ausgangskörper }\{100\} \cdot\{110\} \text {. }
$$

An einen Spaltungswürfel wurden (011), (0T1), (0TT) und (01T) bis zum Verschwinden von (001), (0T0), (00T) und (010) angeschliffen. Dieser Krystallkörper wurde stets auf eine der Rhombendodekaëderflächen aufgekittet, sodaß zwei parallele Würfelflächen und zwei parallele Rhombendodekaëderflächen vertikal standen. Unterwirft man einen derartigen Ausgangskürper (Fig. 9) der Auflösung, so verschieben sich die Rhomben-

Fig. 9.

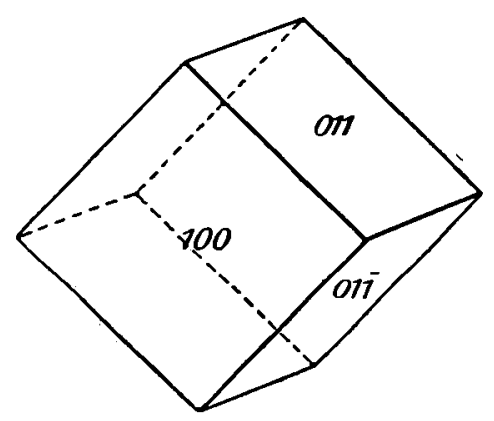

Fig. 10.

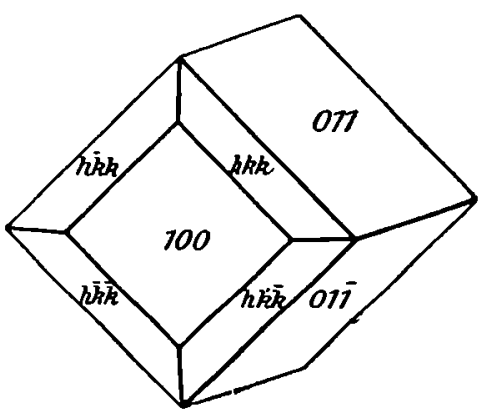

Fig. 11.

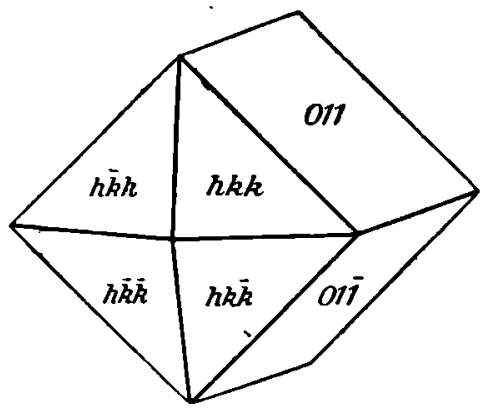

dodekaëderflächen vollkommen parallel und eben; die Kanten der Rhombendodekaëderflächen bleiben scharf. Als Auflösungsflächen auf den Würfelflächen (100) und (T00) entstehen hier sofort Ikositetraëderflächen (Fig. 10). Diese vergrößern sich allmählich und verdrängen die Würfelflächen, sodaß als Endkörper der Auflösung eine Kombination von vier Rhombendodekaëder- und acht Ikositetraëderfächen resultiert (Fig. 11 und Taf. X, Fig. 8). Waren infolge Abspaltens beim Schleifen diese Kanten durch schmale Würfelflächen $(001),(0 T 0),(00 T)$ und $(010)$ abgestumpft, so siedelten sich auch hier lkositetraëderflächen an. Es bilden sich um so schärfere Kanten 
und Ecken, je geringer die Untersättigung ist. Die Neigung der Ikositetraëderflächen zum Würfel nimmt auch hier mit steigender Untersättigung ab. (Tabelle VII.)

Tabelle VII.

$(h k \widehat{k)}(h \hbar \bar{l})$ bei $5 \%$ Harnstoffzusatz und bei verschiedenen Untersättigungsgraden.

\begin{tabular}{|c|c|c|c|c|}
\hline Untersättigung: & Gemessen: & Mittel: & Indices: & Berechnet \\
\hline $0,25 \%$ & $11^{\circ} 53^{\prime}-12^{\circ} 18^{\prime}$ & $12^{\circ} 7^{\prime}$ & 27.2 .2 & $11^{\circ} 571^{\prime}$ \\
\hline 0,5 & $10 \quad 9-10 \quad 56$ & 1029 & 31.2 .2 & $1025 \frac{1}{2}$ \\
\hline 1 & $435-59$ & 454 & 33.1 .1 & 454 \\
\hline 2 & $345-356$ & $350 \frac{1}{2}$ & 42.1 .1 & $351 \frac{1}{2}$ \\
\hline 4 & $246-250$ & 247 & 58.1 .1 & $247 \frac{1}{2}$ \\
\hline
\end{tabular}

Ausgangskörper $\{100\} \cdot\{111\}$.

An diesen Ausgangskörper, der sechs Würfel- und acht Oktaëder1lächen zeigte (Fig. 12), wurde als Kittfläche eine Rhombendodekaëderfläche angeschliffen, soda $ß$ hier ein Würfelflächenpaar und zwei Oktaëderflächenpaare vertikal standen. Als Auflüsungsflächen schieben sich von den Kanten her Ikositetraëderflächen vor. Der Auflüsungskürper stellt zunächst eine

Fig. 12.

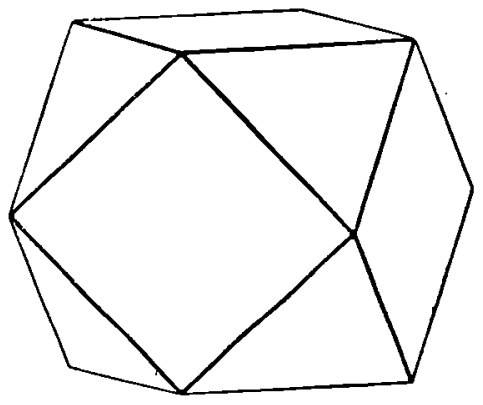

Fig. 13.

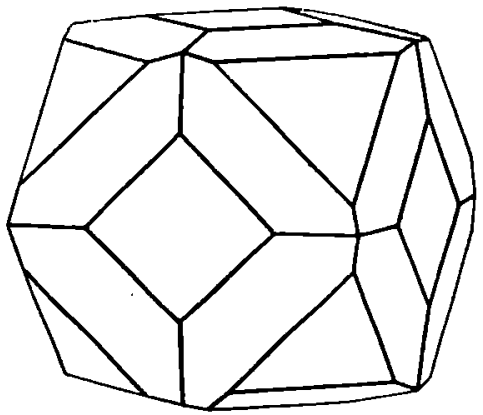

Kombination von Würfel, Oktaëder und Ikositetraëder dar (Fig. 13). Dann werden die Würfelflächen gleich Null, die Ikositetraëderflächen kommen gegeneinander zum Schnitt, sodaß jetzt nur noch Ikositetraëder- und Oktaëderflächen vorhanden sind (Fig. 14 und Taf. $X$, Fig. 11 und 12). Die Oktaëderflächen, deren Verschiebungsgeschwindigkeit relativ gering ist, verschieben sich vollkommen eben und parallel, bis auch sie schließlich von den Ikositetraëderflächen völlig verdrängt werden. An ihrer Stelle bilden sich die dreizähligen Ecken des Ikositetraëders scharf aus; der Endkürper der Auflüsung, das bloße Ikositetraëder, ist erreicht (Fig. 15 und Taf. $X$, Fig. 13). 
Über die Auflösung von Chlornatriumkrystallen in harnstoflhaltigen Lösungen. 303

Die Untersättigung ist auch hier für die Form des Endkörpers von Einfluß. Weniger gekrümmte Flächen mit scharfen Ecken und Kanten bilden sich bei Untersättigungen von $0,25-1 \not \%$; die zweizăhligen Ecken sind an diesen Endkörpern besonders scharf ausgebildet. Die Endkörper bei 2 und $4 \%$ Untersättigung weisen oft starke Verrundungen auf. Deutlich tritt der Einfluß des Untersättigungsgrades auf die Neigungen der lkositetraëderflächen am Endkörper hervor (Tabelle VIII).

Fig. 14.

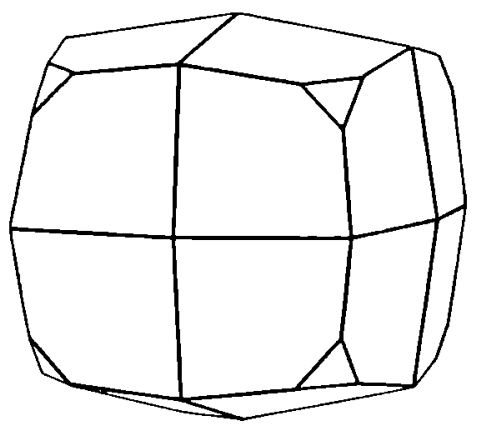

Fig. 15.

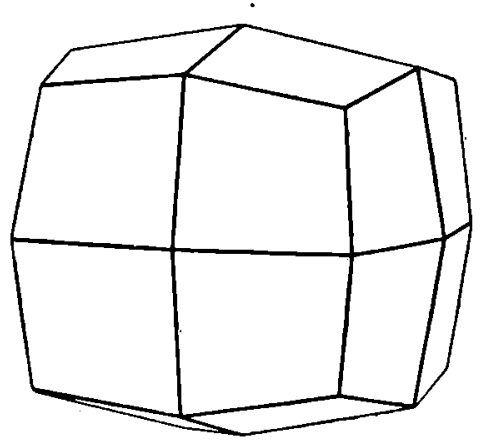

Tabelle VIII.

$(h k \hat{k})(h k \hbar k)$ bei $5 \%$ Harnstoffzusatz und bei verschiedenen Untersättigungsgraden.

\begin{tabular}{|c|c|c|c|c|}
\hline Untersättigung: & Gemessen: & Mitlel: & Indices: & Berechnet \\
\hline $0,25 \%$ & $11^{\circ} 23^{\prime}-12^{\circ} 42$ & $12^{\circ} 22^{\prime}$ & 13.1 .1 & $12^{\circ} 25^{\prime}$ \\
\hline 0,5 & $1041-1158$ & 1138 & 14.1 .1 & 1132 \\
\hline 1 & $613-748$ & 648 & 24.1 .1 & 645 \\
\hline 2 & $430-5 \quad 3$ & 4391 & 35.1 .1 & 440 \\
\hline 4 & $244-251$ & $247 \frac{1}{2}$ & 58.1 .1 & $2 \quad 47 \frac{1}{2}$ \\
\hline
\end{tabular}

Ausgangskörper (Kugel).

An den kugelfürmigen Ausgangskörpern wurde nachträglich, um ihnen einen besseren Halt bei dem Aufkitten auf den kleinen Rührer zu geben, eine beliebige Fläche angeschliflen. Die Orientierung dieser ist für die Ausbildung des Endkürpes von keinem Einfluß; die Kugeln wurden unmittelbar auf das kleine Flügelrad aufgekittet.

Als Beispiel für die Betrachtung der Auflösungserscheinungen sei die Auflösung einer Kugel in einer um 0,25\% untersättigten $5 \%$-harnstoffhaltigen Kochsalzlüsung angeführt. Bei einer Auflösungsdauer von drei Stunden entstehen an den Polen der Oklaëderflächen unregelmäßjg verstreut dreiflächige Ätzgrübchen. Von dem mittelsten, dem tiefsten dieser, geht eine große Anzahl radialstrahlig gruppierter Rinnen aus, die alle ungefähr 
von gleicher Länge sind (Fig. 16). An den Polen von $\{100\}$ fand ich nur selten vierflächige Ätzgrübchen; die übrige Oberfläche bleibt vollkommen glatt. Nach weiteren drei Stunden waren bereits einige der Ätzgrübchen bei $\{111\}$ verschwunden, während sich in den Polen von $\{100\}$ vierflächige Ecken mit kurzen Kanten, der Lage nach Ikositetraëderkanten entsprechend, gebildet hatten (Fig. 17). Im weiteren Verlauf der Auflösung blieb schließlich nur je ein einziges Ätzgrübchen in den Orten von $\{111\}$ übrig. Die radialstrahlige Gruppierung der feinen Rinnen blieb ebenfalls erhalten, nur hatten sich die in der Richtung nach den Polen von $\{110\}$ verlaufenden Rillen verkürzt, während die nach den vierzähligen Ecken gerichteten ihre gleiche Länge behalten hatten. Die oben erwähnten Kanten der vierzähligen Ecken hatten sich beträchtlich verlängert. Der Auflüsungskörper

Fig. 16.

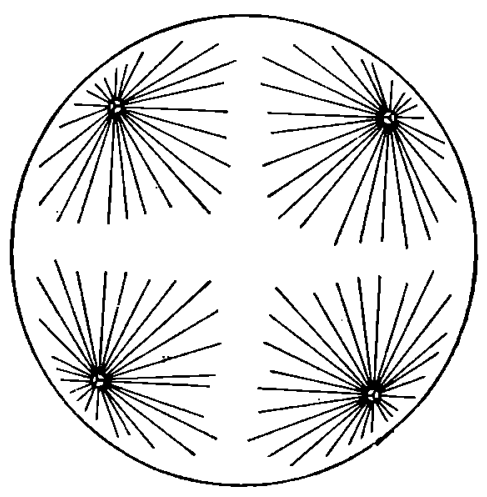

Fig. 17.

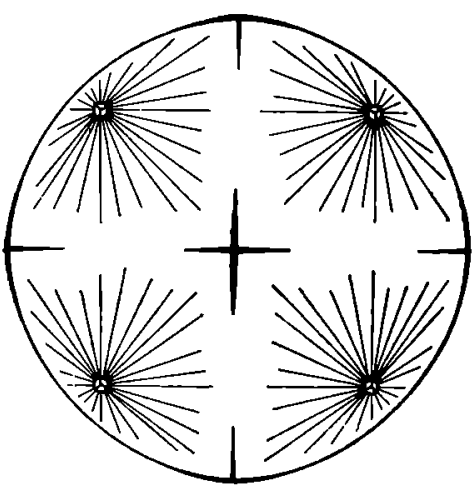

machte den Eindruck einer Kombination von Ikositetraëder und Rhombendodekaëder, bei der die Kombinationskanten von Ikositetraëder und Rhombendodekaëder aus kleinen Rillen zusammengesetzt erschienen. Nach 16stündiger Auflösungsdauer zeigten sich, den Kanten der dreizähligen Ecken des Ikositetraëders entsprechend, kurze Grate, die von dem Ätzgrübchen der Oktaëderpole ausgingen. Die Rillen hatten sich zusehends verflacht, die Kanten der vierzähligen Ecken sich mehr und mehr den zweizähligen Ecken genāhert (Fig. 18). Nach weiteren 16 Stunden, also 32 stündiger Auflösungsdauer, war der Endkörper der Auflösung, das bloße lkositetraëder, nahezu erreicht; die Kanten und Ecken waren mit Ausnahme der zweizähligen Ecken scharf und bis in die Nähe dieser gut ausgebildet. Das Ätzgrübchen in den Orten von $\{111\}$ und die radialstrabligen Rinnen um dieses waren noch vorhanden. Die den Polen von $\{110\}$ entsprechendèn Ecken, die während der Auflüsungsversuche glatt geblieben waren, zeigten nicht mehr das glänzende Aussehen wie vorher, sondern erschienen matt 
mit unscharf ausgebildeten Kanten (Taf. X, Fig. 16). Dieser Auflösungskörper wurde noch 10 Stunden der Auflösung unterworfen, und nun hatte sich als Endkörper ein bloßes Ikositetraëder gebildet. Kanten wie Ecken waren scharf geworden, die zarten Rinnen und das Ätzgrübchen bei $\{111\}$ völlig verschwunden, die gerundeten Flächen des Ikositetraëders selbst glänzend ohne jede Spur eines Ätzgrübchens. Dieser Endkörper (Fig. 19 und Taf. X, Fig. 17) änderte von jetzt an nur seine Größe, während seine Form konstant blieb. Zur Kontrolle der obigen Resultate wurde eine zweite Kugel bei gleicher Untersättigung demselben Lösungsmittel 40 Stunden lang ausgesetzt. Die Erscheinungen bei der Auflösung blieben dieselben.

Im Gegensatz zu V. Goldschmidt konnte ich an den Steinsalzkugeln ausgezeichnete » ̈̈tzreihen « nicht feststellen; die von den Polen von $\{111\}$ ausgehenden Ätzreihen waren radial gestellt und alle von fast gleicher Länge.

Fig. 18.

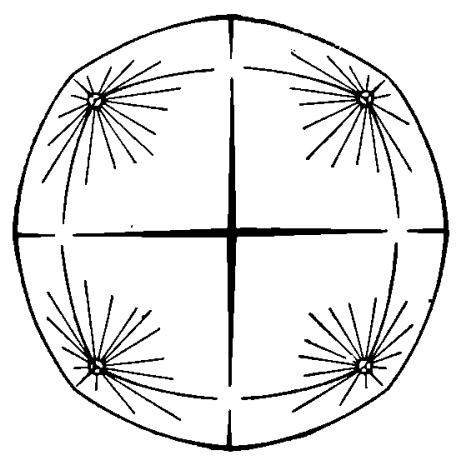

Fig. 19.

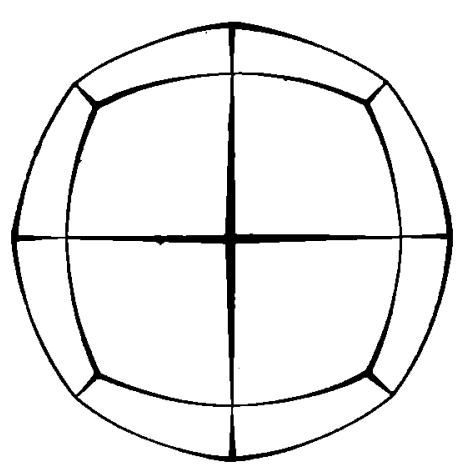

Von diesen bildeten sich nur die von $\{111\}$ nach $\{110\}$ verlaufenden Reihen zu scharfen Kanten aus, die übrigen verschwanden und wurden von den glatten Ikositetraëderflächen überdeckt. An Stelle des Ätzgrübchens bei \{111\} tritt eine scharfe dreizählige Ecke. Die vierzähligen Ecken bei $\{100\}$ und die Kanten von den Polen von $\{100\}$ nach denjenigen von $\{110\}$ treten jedoch sehr früh auf, ohne daß vorher »Ätzreihen a zu beobachten waren.

Nach der von A. Johnsen aufgestellten Theorie umgibt sich der Auflösungskörper einer Kugel mit Flächen von absolut größter Auflösungsgeschwindigkeit. Von allen Flächen, die ursprünglich die Kugel tangieren, werden hier nur die Ikositetraëderflächen, eben infolge ihrer absolut größten Auflösungsgeschwindigkeit, reell.

Man kann die radialstrahlige Gruppierung der feinen Rinnen in den Orten von $\{1 \mid 1\}$ als Spuren einer großen Reihe von Pyramidenwürfeln auffassen, die $\mathrm{zu}$ den Würfelflächen alle Lagen von $0-45^{\circ}$ aufweisen künnen. Diese Flächen haben aber im Verlauf der Auflösung keinen 
Bestand. Denkt man sie ursprünglich alle als tangierende Flächen am Ausgangskörper vorhanden, so sinkt ihre Zahl immer mehr herab. Die Flächen mit größerer Auflösungsgeschwindigkeit schieben sich über die mit geringerer Geschwindigkeit hinweg, und schließlich kommen die Flächen mit absolut größter Auflösungsgeschwindigkeit zum gegenseitigen Schnitt. Die Pyramidenwürfelflächen, die dem Würfel am meisten benachbart sind, werden ähnlich, wie ich es bei dem Auflüsungskörper des Würfels zeigte, infolge ihrer verhältnismäßig geringeren Geschwindigkeit von den Ikositetraëderflächen verdrängt. Bei der Kugel ist der Überschiebungsprozeß der schnelleren Flächen ein anderer als bei dem Würfel. Dort sahen wir, daß die Pyramidenwürfelflächen mit geringerer Neigung gegen den Würfel von den stärker genejgten Pyramidenwürfelflächen und diese von den Ikositetraëderflächen verdrängt wurden, die sich von den dreizähligen Ecken her vorschoben. Bei der Auflüsung der Kugel beginnen die lkositetraëderflächen von den vierzähligen Ecken aus die Überschiebung der Pyramidenwürfelflächen; und zwar werden zuerst die flachsten $\{h k 0\}$, dann allmählich auch die mit größerer Neigung und endlich das Rhombendodekaëder mit seiner Neigung von $45^{\circ}$ gegen den Würfel von ihnen verdrängt.

Die Auflüsungskörper der Kugeln bei 0,5- und 1 proz. Untersättigung lieferten Auflösungserscheinungen von ähnlicher Reihenfolge. Der Endkörper war wiederum ein bloßes Ikositetraëder. Bei 2- und 4 proz. Untersättigung trat die Schärfe der zweizähligen Ecken wieder zurück; die drei- und vierzähligen Ecken behielten ihre Schärfe. Die den Hexaëderkanten benachbarten Ikositetraëderkanten waren gerundet. Diese Endkörper würden daher, wenn die vierzähligen Ecken fehlen würden, einem stark gerundeten, würfelähnlichem Gebilde ähneln. Besonders deutlich sind bei verschiedenen Untersättigungen die Unterschiede in den Neigungswinkeln der dem Würfel benachbarten Ikositetraëderflächen, wie es die Tabelle IX zeigt.

Tabelle IX.

$(h k \hat{k} \widehat{(h \bar{k} \bar{k})}$ bei $5 \%$ Harnstoffzusatz und bei verschiedenen Untersättigungsgraden.

\begin{tabular}{|c|c|c|c|c|}
\hline Untersättigung: & Gemessen: & Mittel: & Indices: & Berechnet: \\
\hline $0,25 \%$ & $14^{\circ} 20^{\prime}-15^{\circ} 18^{\prime}$ & $14^{\circ} 48^{\prime}$ & 11.1 .1 & $14^{\circ} 39^{\prime}$ \\
\hline 0,5 & $11 \quad 10-1247$ & $11 \quad 49 \frac{1}{2}$ & 27.2 .2 & $1157 \frac{1}{2}$ \\
\hline 1 & $714-740$ & 725 & 22.1 .1 & $721 \frac{1}{2}$ \\
\hline 2 & 5 9 - 5 22 & 515 & 31.1 .1 & $5 \quad 13 \frac{1}{2}$ \\
\hline 4 & $354-446$ & 423 & 37.1 .1 & $422 \frac{1}{2}$ \\
\hline
\end{tabular}

Die Auflösung bei $5 \%$ Harnstoflzusatz ergab also in dem Bereich der Untersättigungen von $0,25-4 \%$ als Endkörper ein Ikositetraëder, mochte der Ausgangskörper nun $\{100\}$ oder eine Kombination von $\{100\}$ und $\{111\}$ oder aber eine Kugel sein. Die Neigung der dem Würfel 
Über die Auflösung von Chlornatriumkrystallen in harnstoffhaltigen Lösungen. 307

zunächst liegenden Ikositetraëderflächen ist jedoch für die aus den verschiedenen Ausgangskörpern erhaltenen Endkörper verschieden. Die größte Neigung ergaben die an der Kugel auftretenden Ikositetraëderflächen. Die Kombination von vier Rhombendodekaëder- und zwei Würfelflächen lieferte als Endform eine Kombination von vier Rhombendodekaëderflächen und statt der Würfelflächen von je vier Ikositetraëderflächen. Bei allen angewandten Untersättigungen zeigen am Endkörper die drei- und vierzähligen Ecken die größte Schärfe, während die Schärfe der zweizåhligen Ecken mit zunehmender Untersättigung abnimmt. Die Neigung der Ikositetraëderflächen und auch der Pyramidenwürfelflächen gegenüber den Würfelflächen nimmt mit steigender Untersättigung immer mehr ab.

b) 2. Auflösungskörper und Endkörper der Auflösung bei verschieden-prozentigem Harnstoffzusatz und bei 1 proz. Untersättigung.

Die Auflösungsversuche bei einem Harnstoffgehalt von 10, 20, 40, 60 und $80 \%$ wurden bei 1 proz. Untersättigung vorgenommen. Es wurden dieselben Ausgangskörper wie vorher $(b, 1$.$) der Auflösung unterworfen.$ Die Bedingungen wurden möglichst konstant gehalten, um einen guten Vergleich über die Einwirkung des Harnstoffes zu erreichen.

\section{Ausgangskörper $\{100\}$.}

Unterwirft man einen Würfel in einer um $1 \%$ untersättigten Kochsalzlösung mit $10 \%$ Harnstoffzusatz der Auflösung, so werden hier wiederum die Würfelflächen von den Pyramidenwürfelflüchen verdrüngt. Man erhält als ersten Auflüsungskörper eine Kombination von sechs Würfel- und 24 Pyramidenwürfelflāchen; als zweiter Auflösungskörper bildet sich darauf ein bloßer Pyramidenwürfel. Sobald die Pyramidenwürfelflächen miteinander zum Schnitt gekommen sind, werden die Ikositetraëderflächen von den dreizähligen Ecken her reell. Sie drängen die eben reell gewordenen Pyramidenwürfelflächen immer mehr in das virtuelle Reich zurück. Als Endkörper der Auflösung resultiert ein Ikositetraëder, dessen drei- und vierzählige Ecken scharf, dessen zweizählige Ecken jedoch nicht ausgebildet erscheinen. Die den Hexaëderkanten benachbarten Ikositetraëderkanten sind scharf, während die von den vierzähligen Ecken ausgehenden Ikositetraëderkanten kurz vor dem Ort der zweizähligen Ecken aufhören.

Die Auflüsungskörper des Würfels bei höherem Harnstoffgehalt durchlaufen die gleichen Auflösungskörper. Die Flächen werden jedoch immer verrundeter und bei $40-80 \%$ Harnstoffzusatz bleibt von der vierzähligen Ecke nur ein ganz kleiner, aber deutlich vierstrahliger Stern übrig (Taf. X, Fig. 6 bei $40 \%$ Harnstoffzusatz und Fig. 7 bei $80 \%$ Harnstoffzusatz). Die 
Messung der Neigungswinkel der an dieser Ecke auftretenden Flächen erwies sich als nicht möglich. Die Winkelmessungen der Pyramidenwürfelflāchen zeigen auch hier ein Ansteigen in der Größe ihrer Neigung während des Auflüsungsprozesses (vgl. Tabelle III und IV, S. 299). Die Neigung der Pyramidenwürfelflächen zum vizinalen Würfel nimmt bis zu $20 \%$ Harnstoffzusatz ab, ergibt aber bei $40-80 \%$ Harnstoffzusatz fast gleiche Werte. Die Ikositetraëderflächen zeigen ein noch deutlicheres Fallen der Winkelwerte hei höherem Harnstoffgehalt (Tabelle X). In den folgenden Tabellen sind zum Vergleich die Winkel der Auflösungsflächen, die aus Lösungen mit $5 \%$ Harnstoffzusatz und bei 1 proz. Untersättigung erhalten wurden, noch einmal mit angeführt.

Tabelle X.

Neigungswinkel der Pyramidenwürfel- und Ikositetraëderflächen bei wechselndem Harnstoffzusatz und bei 1 proz. Untersättigung.

\begin{tabular}{|c|c|c|c|c|}
\hline \multirow{2}{*}{$\begin{array}{c}\text { Harnstoffzusatz } \\
\text { in } \%\end{array}$} & \multicolumn{4}{|c|}{ Neigungswinkel $(h k 0 \widehat{(h} \bar{k} 0)$} \\
\hline & Gemessen: & Mittel: & Indices: & Berechnet: \\
\hline $\mathbf{5}$ & $2^{\circ} 38^{\prime}-3^{\circ} 47^{\prime}$ & $2^{\circ} 56^{\prime}$ & 39.1 .0 & $2^{\circ} 56^{\prime}$ \\
\hline 10 & $24-240$ & 228 & 46.1 .0 & 226 \\
\hline 20 & $139-237$ & $2 \quad 2$ & 56.1 .0 & 23 \\
\hline 40 & $\begin{array}{llll}3 & 33-4 & 34\end{array}$ & 46 & 28.1 .0 & $4 \quad 5 \frac{1}{2}$ \\
\hline 60 & $324-4 \quad 19$ & 354 & 29.1 .0 & 357 \\
\hline 80 & $326-4 \quad 43$ & 40 & $28,5.1 .0$ & 41 \\
\hline \multicolumn{5}{|c|}{ Neigungswinkel $(h k k \widehat{(h} k \bar{k})$} \\
\hline 5 & $7^{\circ} 50^{\prime}-8^{\circ} 55^{\prime}$ & $8^{\circ} 18^{\prime}$ & 19.1 .1 & $8^{\circ} 31^{\prime}$ \\
\hline 10 & $335-44$ & 351 & 42.1 .1 & $351 \frac{1}{2}$ \\
\hline 20 & $312-356$ & 330 & 46.1 .1 & $331 \frac{1}{2}$ \\
\hline
\end{tabular}

An diesen Ausgangskörpern konnte ähnlich wie bei den Versuchen mil $5 \%$ Harnstoffzusatz wiederum die Beobachtung gemacht werden, daß sich die Rhombendodekaëderflächen vollkommen eben und parallel verschieben, wäbrend die Würfelflächen wieder von Ikositetraëderflächen verdrängt werden. Die Endkörper der Auflüsung bei verschiedenem Harnstoffgehalt unterscheiden sich nur wenig voneinander. Die Ikositetraëderkanten der vierzähligen Ecken treten auch hier bei steigendem Harnstoffzusatz allmählich aus der Nachbarschaft der zweizähligen Ecken zurück (Taf. X, Fig. 9 bei $40 \%$ Harnstoffzusatz und Fig. 10 bei $80 \%$ Harnstoffzusatz). Die Ikositetraëderflächen sind auch bei höherem Harnstoffgehalt noch gut meßbar, da die Flächen gut ausgebildet sind und in der Nähe der vierzähligen Ecken durch verhältnismäßig scharfe Kanten sich gegenseitig abgrenzen (Tabelle XI). 
Über die Auflösung von Chlornatriumkrystallen in harnstoffhaltigen Lösungen. 309

Tabelle XI.

Neigungswinkel $(h k k \widehat{(h \hbar} \bar{k})$ bei wechselndem Harnstoffzusatz und bei 1 proz. Untersättigung.

\begin{tabular}{|c|c|c|c|c|}
\hline Harnstoffzusatz: & Gemessen: & Mittel: & Indices: & Berechnet: \\
\hline $5 \%$ & $4^{\circ} 35^{\prime}-5^{\circ} \quad 9^{\prime}$ & $4^{\circ} 5 t^{\prime}$ & 33.1 .1 & $4^{\circ} 54^{\prime}$ \\
\hline 10 & $336-420$ & 358 & 41.1 .1 & 3507 \\
\hline 20 & $\begin{array}{llll}3 & 12-3 & 48\end{array}$ & 331 & 46.1 .1 & $3 \quad 31 \frac{1}{2}$ \\
\hline 40 & $344-442$ & 411 & 39.1 .1 & 49 \\
\hline 60 & $\begin{array}{llll}3 & 28 & -4 & 43\end{array}$ & 43 & 40.1 .1 & 43 \\
\hline 80 & $332-426$ & 42 & 40.1 .1 & 4 \\
\hline
\end{tabular}

Die Beobachtung, daß die Rhombendodekaëderflächen sich vollkommen eben und parallel miteinander verschieben, veranlaßte mich, ein modellartiges Rhombendodekaëder herzustellen. Trotz größter Sorgfalt gelang es mir nur zwei vierzählige Ecken scharf zu erhalten, während die anderen durch kleine Würfelflächen abgestumpft waren. Die dreizähligen Ecken waren vollkommen scharf ausgebildet. Die Durchmesser parallel den zweizähligen Ecken betrugen rund 22,3 mm. Dieser Ausgangskörper, welcher der Auflösung in einer um $1 \%$ untersältigten $80 \%$ Harnstoff enthaltenden Kochsalzlösung unterworfen wurde, war auf eine der abgespaltenen Würfelflächen aufgekittet. Nach einer Auflösungsdauer von 23 Stunden zeigte der Körper seine alte Form. Die Flächen hatten sich parallel und vollkommen glatt verschoben und zwar um rund $3,9 \mathrm{~mm}$; Kanten und Ecken waren scharf geblieben. Die Winkelmessungen ergaben vor der Auflösung $\left(110 \widehat{)(110)}=90^{\circ} \pm \frac{1}{2}^{\circ}\right.$ und $\left(110 \widehat{(101)}=60^{\circ} \pm \frac{1}{2}^{\circ}\right.$, nach der Auflösung $\left(110 \widehat{(1 T 0)}=91^{\circ} \pm 11^{\circ}\right.$ und $\left(110 \widehat{(101)}=61^{\circ} \pm 11^{\circ}\right.$ als mitlere Werte. Die Abweichungen in den Winkelwerten nach der Auflüsung sind auf die durch den Ansturm der bewegten Lösung hervorgerufene Verzerrung zurückzuführen. Die Ikositetraëderflächen können sich hier infolge der zu großen Urpunktsdistanz nicht realisieren; nur an den durch kleine Würfelflüchen abgestumpften vierzähligen Ecken wurden sie reell, indem sich schwache Verrundungen mit einem vierstrahligen Sternchen bildeten (Taf. X, Fig. 21). Ein modellartiges Rhombendodekaëder liefert demnach als Endkörper der Auflösung wiederum ein modellartiges Rhombendodekaëder.

$$
\text { Ausgangskörper }\{100\} \cdot\{111\} \text {. }
$$

Die Ausgangskörper dieser Art zeigen bei der Auflösung in harnstoffhaltigen Kochsalzlösungen von hohem Harnstoffgehalt ähnliche Erscheinungen wie bei $5 \%$ Harnstoffzusatz. Die Würfelflächen werden zuerst von den schnelleren Ikositetraëderflächen verdrängt; im weiteren Verlauf der Auflösung verschwinden auch die Oktaëderflächen, und an ihrer Stelle 
treten die dreizähligen Ecken des Ikositetraëders auf. Die zweizähligen Ecken erscheinen bei 10 und $20 \%$ Harnstoffzusatz verrundet, bei $40-80 \%$ sind sie durch gekrümmte Kanten ersetzt, die den Hexaëderkanten benachbart sind (Taf. X, Fig. 14 bei $40 \%$ und Fig. 15 bei $80 \%$ Harnstoffzusatz). Die Ikositetraëderflächen an den vierzähligen Ecken sind gut ausgebildet, sodaß ihre Neigung am Goniometer ermittelt werden konnte (Tabelle XII).

\section{Tabelle XII.}

Neigungswinkel $(h k k) \widehat{(h \hbar k)}$ bei wechselndem Harnstoffzusatz und bei 1 proz. Untersâttigung.

\begin{tabular}{|c|c|c|c|c|}
\hline $\begin{array}{c}\text { Harnstoffzusatz: } \\
5 \%\end{array}$ & $\begin{array}{c}\text { Gemessen: } \\
6^{\circ} 13^{\prime}-7^{\circ} 48^{\prime}\end{array}$ & $\begin{array}{l}\text { Mittel: } \\
6^{\circ} 48^{\prime}\end{array}$ & $\begin{array}{l}\text { Indices: } \\
24.1 .1\end{array}$ & $\begin{array}{c}\text { Berechnet: } \\
6^{\circ} 44_{\frac{1}{2}}^{\prime}\end{array}$ \\
\hline 10 & $452-535$ & 515 & 31.1 .1 & $513 \frac{1}{2}$ \\
\hline 20 & $4 \quad 13-458$ & 438 & 35.1 .1 & 4371 \\
\hline 40 & $351-4 \quad 46$ & 413 & $38,5.1 .1$ & $4 \quad 12 \frac{1}{2}$ \\
\hline 60 & $45-4 \quad 17$ & 413 & $38,5.1 .1$ & $4 \quad 12 \frac{1}{2}$ \\
\hline 80 & $335-429$ & 43 & 40.1 .1 & 3 \\
\hline
\end{tabular}

Ausgangskürper (Kugel).

Bei 10 und $20 \%$ Harnstoflzusatz entstehen beim Auflösen einer Kugel an den Orten der Oktaëderflächen Ätzgrübchen, von denen aus radialstrahlig kurze zarte Rinnen verlaufen. Die Pole von $\{100\}$ zeigen selten Ätzgrübchen. Die übrige Oberfläche bleibt glatt. Allmählich bilden sich in den Zonen $[111,110]$ kurze scharfe Kanten, die kurz vor den Polen von $\{110\}$ verrunden. Die Ätzgrübchen bei $\{111\}$ sowie die feinen zarten Rillen verschwinden, und an ihrer Stelle entstehen scharfe dreiflächige Ecken. An den Orten der Würfelflächen bilden sich vierflächige Ecken mit kurzen unscharfen Kanten, die von den Polen von $\{100\}$ nach denjenigen von $\{110\}$ hinziehen. Die zweizähligen Ecken des Ikositetraëders zeigen dagegen eine starke Verrundung. Der Endkörper der Auflösung ähnelt der Form eines verrundeten Ikositetraëders mit glatten Flächen, dessen Kanten nur in der Nähe der drei- und vierzähligen Ecken scharf hervortreten (Taf. X, Fig. 18 bei 20\% Harnstoffzusatz).

Kugeln, die in Lösungen von 40,60 und $80 \%$ Harnstoffzusatz der Auflösung unterworfen wurden, zeigen untereinander gleiche, aber von den eben genannten verschiedene Auflösungserscheinungen. Schon nach kurzer Einwirkung des Lösungsmittels bilden sich Ätzgrübchen an den Orten von $\{111\}$ und öfters auch von $\{100\}$. Die radialstrahlige Anordnung feiner Rillen ist nicht nur an den Polen von $\{111\}$ sondern auch von $\{100\}$ zu beobachten. Die Rillung um $\{111\}$ erstreckt sich besonders weit in der Richtung der Zone $\{111,110]$, wo sie fast bis an die Pole von $\{110\}$ heranreicht. Im weiteren Verlauf der Auflösung bilden sich scharfe Ecken im 
Ort der Oktaëderflächen und von ihnen ausgehend scharfe, etwas gekrümmte Kanten, die den Hexaëderkanten benachbart sind. Die Oberfläche in der Nähe dieser ist glatt und glänzend, während sie an den Orten von $\{100\}$ infolge der noch vorhandenen feinen Rillung matt erscheint. Diese verschwindet jedoch, und an ihrer Stelle bildet sich eine ganz kleine vierflächige Ecke. Würden diese Ecken fehlen, so würde der Endkörper einem Hexaëder ähneln, dessen Kanten und Ecken stark gekrümmt sind (Taf. X, Fig. 19 bei $40 \%$ und Fig. 20 bei $80 \%$ Harnstoffzusatz). Winkelmessungen an diesen Endkörpern waren jedoch nicht möglich.

Wenn man die Resultate der obigen Untersuchungen über Auflüsungskörper von Steinsalzkrystallen in Kochsalzlösungen mit verschiedenem Harnstoffgehalt, die um $1 \%$ untersättigt sind, vergleicht, so zeigt sich, soweit die Formbeeinflussung in Betracht gezogen wird, ein deutlicher Unterschied in den Auflösungs- und Endkörpern. Die Versuche mit $5 \%$ Harnstoffzusatz ergeben ähnliche Auflösungskörper wie die aus $1 \%$ untersättigter reiner Chlornatriumlösung erhaltenen Auflösungskörper 1). Je höher der Harnstoffgehalt steigt, destomehr verschwinden die Kanten des Ikositetraëders nach den zweizïhligen Ecken hin, bis sie schließlich auf $\{100\}$ nur noch flache Ecken in Form eines kleinen vierstrahligen Sternes bilden. Die zweizäbligen Ecken verschwinden ebenfalls, und bei einem Harnstoffgehalt von $40 \%$ und höher werden sie von einer gekrümmten scharfen Kante überspannt, die die dreizähligen Ecken verbindet. Letztere Ecken behalten ihre Schärfe. Die Auflösungskörper der Kugeln liefern das beste Vergleichsmaterial hierfür.

Ein deutlicher Unterschied zeigt sich auch in den Neigungswinkeln der Auflösungsflächen; je höher der Harnstoffgehalt steigt, umso geringer wird die Neigung, während von $40 \%$ Harnstoffzusatz an die Werte einander gleich bleiben. Man könnte hier von einem »Höhenwert der Formbeeinflussung in der Umgebung von $40 \%$ Harnstoffzusatz sprechen, wie ihn Fastert ${ }^{2}$ ) bei seinen Wachstumsuntersuchungen am Steinsalz feststellte, während der »Schwellenwert « der beginnenden Formbeeinflussung bei ungefähr $10 \%$ Harnstoffzusatz zu suchen wäre. Vergleicht man die Wachstums- mit den Auflösungserscheinungen, so zeigt es sich, daß in dem Harnstoffbereich, wo beim Wachstum der Würfel vorherrscht, bei der Auflösung die vierzählige Ecke des Ikositetraëders eine besondere Rolle spielt. Bei der Kugel bildet sie sich bei $5 \%$ Harnstoffzusatz vor der dreizähligen Ecke aus. Je höher der Harnstoffgehalt steigt, desto mehr tritt beim Wachstum das Oktaëder in die Erscheinung, bis ron $40 \%$ Harnstoffzusatz an der Höhenwert erreicht ist, das Steinsalz in Form von Oktaëdern

1) W. Poppe, l. c.

2) C. Fastert, l. c. 
auskrystallisiert. Bei der Auflösung nimmt bei höherem Harnstoffzusatz die Schärfe der vierzäbligen Ecke immer mehr ab, während die in den Orten von $\{111\}$ auftretende dreizählige Ecke immer schärfer wird. Von $40 \%$ Harnstoffzusatz an bildet sie sich lange vor der vierzähligen Ecke aus.

Es zeigt sich also hier die Erscheinung, daß bei dem Endkörper der Auflösung scharfe Ecken an den Polen derjenigen Flächen sich bilden, welche an dem Endkörper des Wachstums vorherrschen, wenn sich Auflösung und Wachstum bei gleichem Harnstoffgehalt vollziehen.

Bei der Formbeeinflussung durch Harnstoffzusatz scheinen Schwellen- und Höhenwert sowohl für das Wachstum wie für die Auflösung die gleichen Werte zu haben.

\section{B. Über die Auflösungsgeschwindigkeit verschiedenartiger Krystallflächen.}

\section{Frühere Beobachtungen.}

Mit der Ermittelung der Auflösungsgeschwindigkeit verschiedenartiger Krystallfächen baben sich eine Reihe von Forschern beschäftigt. Sie finden im allgemeinęn den Satz bestätigt, daß Auflösungs- und Wachstumsgeschwindigkeiten eines Krystalles in verschiedener Richtung sich verschieden verhalten. Die bereits erwähnten Versuche von Lavizzari und von 0 . Meyer bestätigen dieses. Eine ausführliche Angabe der Arbeiten über Wachstums- und Auflösungsgeschwindigkeiten findet sich bei A. Ritzel1). Nach Becke2) umgibt sich der Krystallkörper sowohl beim Wachstum wie bei der Auflösung mit den Flächen größten Lüsungswiderstandes, während nach A. Johnsen ${ }^{9}$ ) der Endkörper des Wachstums durch Flächen mit absolut kleinsten Wachstumsgeschwindigkeiten und der Endkörper der Auflüsung durch Flächen mit absolut größten Auflösungsgeschwindigkeiten begrenzt wird. G. Wulff ${ }^{4}$ ) fand, daß die Wachstums- und Auflösungsgeschwindigkeiten der Krystallflächen des Mohr'schen Satzes durchaus nicht reziprok sind. Mit Wulff führt Andrejew ${ }^{5}$ ) das Nichtvorhandensein der Reziprozität $\mathrm{zwischen} \mathrm{Wachstums-} \mathrm{und} \mathrm{Auflösungsgeschwindigkeit} \mathrm{auf} \mathrm{das}$ Auftreten von Ätzgrübchen zurück. A. Körbs ${ }^{6}$ ) fand die Lösungsgeschwindigkeit verschiedener Flächenarten am Steinsalz nur in sehr geringem Maße

1) A. Ritzel, Fortschrilte d. Min. usw. 1911, 1, 86.

2) Becke, Tscherm. Min. petr. Mitteil. 1885, 7, 200; 1886, 8, 206 u. 1889, 11, 349. Ref. diese Zeitschr. 12, 287; 17, 200; 21, 185.

3) A. Johnsen, l. c.

4) G. Wulff, diese Zeitschr. 1899, 30, 309 u. 1901, 34, 449.

3) Andrejew, diese Zeitschr. 1907, 43, 39.

6) A. Körps, diese Zeitschr. 1907, 43, 433. 
Über die Auflösung von Chlornatriumkrystallen in harnstoff haltigen Lösungen. 313

verschieden; dagegen konnte er bei Kupfervitriol, Weinsäure und Gelbblutlaugensalz Unterschiede bis zu $86 \%$ feststellen.

Eine Abhüngigkeit der Auflösungsgeschwindigkeit von dem Untersättigungsgrade stellten zuerst Noyes und R. Whitne ${ }^{1}$ ) fest. Die Auflösungsgeschwindigkeit ist proportional dem Konzentrationsgefälle

$$
d x=k .0 .(C-c) d t,
$$

wo $C$ die Konzentration der gesättigten Lösung, $c$ die augenblickliche Konzentration, $x$ die bereits aufgelöste Menge, $t$ die Zeit, $O$ die Oberfläche und $k$ einen von dem Lösungsmittel und der Krystallfläche abhängigen Geschwindigkeitskoëffizienten bedeuten. Nernst ${ }^{2}$ ) zeigte dann, daß sich diese Theorie auf alle Reaktionen in heterogenen Systemen anwenden läßt, wenn man annimmt, daß sich das Gleichgewicht an der Trennungsschicht zweier Phasen mit praktisch unendlich (d. h. im Vergleich zur Diffusionsgeschwindigkeit) großer Geschwindigkeit einstellt. E. Brunner ${ }^{3}$ ) bestätigte diese Theorie an einer Reihe von Stoffen. Er findet, daß die Auflösungsgeschwindigkeit der Potenz ${ }_{-2}^{2}$ der Rührgeschwindigkeit proportional ist, während L. Bruner und St. Tolloczko ${ }^{4}$ ) die Auflösungsgeschwindigkeit direkt proportional der Rührgeschwindigkeit fanden. Johnsen (l. c.) betonte, daß der Geschwindigkeitskoëffizient $k$ für verschiedenartige Krystallflächen auf Grund ihrer verschiedenen Verschiebungsgeschwindigkeiten als verschieden anzunehmen sei und sich daher auch während der Auflösung, wofern sich hierbei der Habitus ändert, ändern müsse. Ritzelb) glaubt dagegen annehmen zu dürfen, daß alle am Steinsalz möglichen Flächen bei gleichbleibender Untersättigung für $k$ einen innerhalb der Fehlergrenzen gleichen Wert liefern. Poppe (l. c.) kommt jedoch auf Grund seiner Resultate über die Auflösungsgeschwindigkeiten verschiedenartiger Krystallflächen am Steinsalz in Übereinstimmung mit Johnsen zu dem Ergebnis, daß man für verschiedenartige Flächen verschiedene Werte von $k$ annehmen müsse, um nicht unmöglich große Differenzen in den Süttigungskonzentrationen (s Löslichkeiten « bei Ritzel) zu erhalten.

Auch ich fand bei meinen Berechnungen, wenn ich $k$ als gleich für verschiedenartige Flächen annehme, bedeutend größere Unterschiede in den Sättigungskonzentrationen für den Würfel und das Oktaëder in harnstoffhaltigen Lösungen als die von Ritzel angegebenen. Außerdem würde die Süttigungskonzentration der Würfelflüche bereits bei 5 q Harnstoff-

1) Noyes und R. Whitney, Z. f. phys. Chem. 1897, 23, 689.

2) Nernst, Z. f. phys. Chem. 1904, 47, 52.

3) E. Brunner, Z. f. phys. Chem. 1904, 47, 56.

4) L. Bruner und St. Tolloczko, Anz. d. Acad. d. Wiss. Krakau 1907, 603; Ref. d. Z. 1911, 48, 524 und Z. f. anorgan. Chem. 1908, 56, 58; Ref. d. Z. 1911, 49, 625. 5) Ritzel, diese Zeitschr. 1911, 49, 1 эั9. 
zusatz eine größere sein als die der Óktaëderfläche; mit steigendem Harnstoffgehalt würde der Unterschied in den Sättigungskonzentrationen immer mehr zunehmen. Da Poppe fand, daß bei Ritzel's Annahme von gleichem $k$ für ungleiche Flächen in reiner Lösung der Würfel und nicht das Oktaëder die größere Sättigungskonzentration besitzt, so würde demnach durch Harnstoffzusatz nicht eine Umkehrung, sondern eine Erhöhung des Unterschiedes der Sättigungskonzentrationen für den Würfel und das Oktaëder eintreten (Tabelle XIII).

Tabelle XIII.

\begin{tabular}{c|c|c|c|c|c|c|c}
\hline Harnstoffzusatz in \% & 0 & 5 & 10 & 20 & 40 & 60 & 80 \\
\hline$C_{W}-C_{0}$ bei gleichem $k$ & $\begin{array}{c}0,09 \\
(\text { Poppe })\end{array}$ & 0,08 & 0,08 & 0,11 & 0,13 & 0,19 & 0,22
\end{tabular}

In der Tabelle XIII bedeutet $C_{W}$ die Sättigungskonzentration der Würfelfläche, $C_{0}$ die der Oktaëderfläche. Die Werte sind bezogen auf $100 \mathrm{~g} \mathrm{H}_{2} \mathrm{O}$ und nach den Werten der Tabellen II und XXVI für um $1 \%$ untersättigte Lösungen berechnet, wobei

$$
\frac{v_{100}}{v_{111}}=\frac{C_{W}-c}{C_{0}-c}
$$

gesetzt wurde; in dieser Gleichung sind $v_{100}, v_{111}, c$ und $C_{W}$ bzw. $v_{100}, v_{111}$, $c$ und $C_{0}$ bekannt, woraus sich $C_{0}$ bzw. $C_{W}$ ergibt. Für das Verbältnis der Auflösungsgeschwindigkeiten von Würfel und Oktaëder ergeben sich, wenn man $k$ als gleich annimmt, viel größere Unterschiede als die von mir gefundenen; so müßte sich bei $5 \%$ Harnstoffzusatz und bei 0,25 proz. Untersättigung die Würfelfläche 9,0 mal schneller auflösen als die Oktaëderfläche, während ich das Verhältnis $\frac{v_{100}}{v_{111}}=1,8$ fand. Man wird also, um nicht allzu große Unterschiede in den Sättigungskonzentrationen zu erhalten, entgegen Ritzel und mit Johnsen ein verschiedenes $k$ für verschiedenartige Flächen annehmen müssen.

\section{Eigene Beobachtungen.}

Die Auflösungsgeschwindigkeiten der Würfel-, Rhombendodekaëder- und Oktaëderflächen am Steinsalz in harnstoffhaltigen Kochsalzlösungen.

Für diese Untersuchungen gelten dieselben Anordnungen wie für die Versuche über Auflösungskörper. Die Auflösungsgeschwindigkeit einer Fläche, unter der ich nach A. Johnsen die Normalengeschwindigkeit ihrer Parallelverschiebung verstehe, wurde ermittelt, indem ich 
Über die Auflösung von Chlornatriumkrystallen in harnstoff haltigen Lösungen. 315

mittelst einer Schublehre, die $0,01 \mathrm{~mm}$ abzulesen gestattete, die Zentraldistanzen bestimmte. Der Ablesungsfehler war bei ebenen Flächen $\pm 0,01 \mathrm{~mm}$, bei gekrümmten Flächen bis $\pm 0,03 \mathrm{~mm}$. Es wurden nur die Zentraldistanzen derjenigen Flächen in Betracht gezogen, die parallel den Axen der Rührer lagen. Ich ermittelte stets die Distanzen paralleler Gegenflächen und damit die doppelte Zentraldistanz der betreffenden Fläche. Die Versuchsbedingungen wurden möglichst konstant gehalten. Untersucht wurden die Auflösungsgeschwindigkeiten in Kochsalzlösungen mit $\mathbf{5 \%}$ Harnstoffzusatz, die um $0,25,0,5,1,2$ und $4 \%$ untersättigt waren; ferner die Auflüsungsgeschwindigkeiten bei 1 proz. Untersättigung in Lösungen mit 10, $20,40,60$ und $80 \%$ Harnstoffzusatz.

a) Die Auflösungsgeschwindigkeiten bei verschiedener Untersättigung in Kochsalzlösungen mit $5 \%$ Harnstoffzusatz.

Die Auflösungsgeschwindigkeiten der Würfelfläche und der ihr vicinalen Pyramidenwürfel- und Ikositetraëderflächen am Ausgangskörper $\{100\}$.

Bei 0,25 - und bei 0,5 proz. Untersättigung blieb die Würfelfläche in den ersten Stadien der Auflösung reell, soda $B$ ihre Verschiebungsgeschwindigkeit $\left(v_{W}\right)$ direkt ermittelt werden konnte. Bei weiterer Auflösung sowie bei höheren Untersättigungsgraden wurde sie von ihr vicinalen Pyramidenwürfel- und Ikositetraëderflächen verdrängt. In dem letzteren Falle wurde die Verschiebung der vierzähligen Ecken gemessen. Aus diesem Werte ließe sich die wahre Verschiebungsgeschwindigkeit der auftretenden $(h k 0)$ und $(h k l)$ durch Multiplikation mit dem Kosinus des Neigungswinkels der Flächen gegen die Würfelfläche ermitteln, wenn ein ganz bestimmter Pyramidenwürfel oder ein ganz bestimmtes Ikositetraëder aufträte. Wie ich aber oben (S. 298) für die Pyramidenwürfelflächen gezeigt habe, ändern sich bei fortschreitender Auflösung die Winkelwerte. Die Verschiebungsgeschwindigkeit der vierzähligen Ecke müßte demnach im Verlauf des Auflösungsvorganges allmählich zunehmen und erst dann gleiche Werte ergeben, wenn mit dem Endkörper der Auflösung eine konstante Form erreicht ist. Die Änderung der Verschiebungsgeschwindigkeit, die durch die Multiplikation mit dem Kosinus des Neigungswinkels bewirkt wird, beträgt jedoch für die von mir ermittelten größten Winkelwerte nur zwei Linheiten in der zweiten Dezimale, liegt also innerhalb der bei den Dickenmessungen erhaltenen Fehlergrenze. Man kann demnach die miltleren Werte direkt als die Auflösungsgeschwindigkeiten der dem Würfel vicinalen Flächen betrachten. (In den Tabellen mit $v_{100}$ bzw. $V_{100}$ bezeichnet.)

Die Verschiebungsgeschwindigkeiten der erst virtuellen, dann reell werdenden Pyramidenwürfel- und Ikositetraëderflächen können aber auf 
indirektem Wege ermittelt werden, wenn man folgendes Verfahren einschlägt. Bedeuten in Fig. $20 a$ die halbe Länge der Würfelkante, $s$ die gemessene Verschiebung der vierzähligen Ecke, $s^{\prime}$ den Weg, den die in der Würfelkante erst virtuell tangierende, später reell werdende Pyramiden-

Fig. 20.

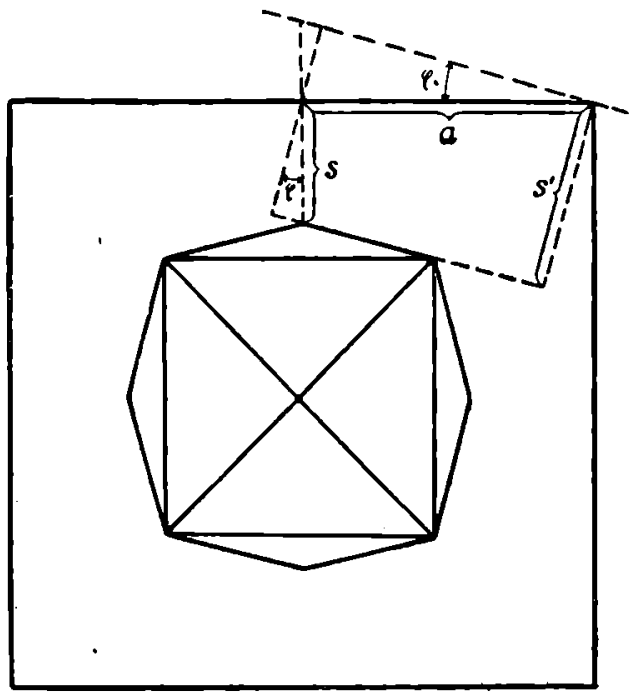

würfelfläche zurückgelegt hat, $\varphi$ den äußeren Neigungswinkel der Pyramidenwürfelfläche gegen die Würfelfläche, so ist

$$
s^{\prime}=a \cdot \sin \varphi+s \cdot \cos \varphi .
$$

Ist $t$ die Versuchsdauer, nach welcher $s$ und $\varphi$ ermittelt wurden, so folgt für die Verschiebungsgeschwindigkeit der Pyramidenwürfellläche

$$
v^{\prime}=\frac{s^{\prime}}{t}=\frac{1}{t}(a \cdot \sin \varphi+s \cdot \cos \varphi) .
$$

Für die Verschiebungsgeschwindigkeit der Ikositetraëderfläche $v^{\prime \prime}$ gilt die gleiche Formel, nur muß für $a$ die Länge der halben Würfelflächendiagonale $=d$ und für $\varphi$ der äußere Neigungswinkel der Ikositetraëderfläche gegen die Würfelfläche $=\psi$ eingesetzt werden. Es folgt

$$
v^{\prime \prime}=\frac{1}{t}(d \cdot \sin \psi+s \cdot \cos \psi)
$$

Die von mir auf diese Weise ermittelten Verschiebungsgeschwindigkeiten der Pyramidenwürfel- und Ikositetraëderflächen gelten für die dem Würfel am nächsten liegenden Flächen, deren Neigungswinkel allein gemessen wurden. Für die folgenden Tabellen mögen nachstehende Abkürzungen gewählt werden: Nr. $=$ Nummer des Versuches, $t=$ Versuchsdauer in Stunden, $v=$ der nach $t$ Stunden gemessene Verschiebungsbetrag in $\mathrm{mm}$, 
Über die Auflösung von Chlornatriumkrystallen in harnstoffhaltigen Lösungen. 317

$V=$ mittlere Verschiebungsgeschwindigkeit in $\mathrm{mm}$ pro Stunde, T.Z. = Tourenzahl des großen Glasrührers pro Minute.

Die Versuche, nach denen die Verschiebungsgeschwindigkeiten der Pyramidenwürfelflächen ermittelt wurden, sind mit einem Stern $\left(^{*}\right)$ versehen; die Verschiebungsgeschwindigkeit der Ikositetraëderflächen wurde jedesmal nach dem Endversuch berechnet.

Tabelle XIV.

Die Verschiebungsgeschwindigkeiten der Würfelflächen und der ihr vicinalen Pyramidenwürfel- und Ikositetraëderflächen bei verschiedenen Untersättigungsgraden.

\begin{tabular}{|c|c|c|c|c|c|c|c|}
\hline Untersättigung: & Nr. & $t$ & $v_{100}$ & $v_{010}$ & Mittel & $V_{100}$ & T.Z. \\
\hline \multirow[t]{10}{*}{$0,25 \%$} & 1 & 1 & 0,09 & 0,08 & 0,085 & 0,085 & 130 \\
\hline & 2 & $1 \frac{1}{2}$ & 0,13 & 0,11 & 0,12 & 0,08 & 125 \\
\hline & 3 & $1 \frac{1}{2}$ & 0,12 & 0,12 & 0,12 & 0,08 & 130 \\
\hline & 4 & 2 & 0,17 & 0,18 & 0,175 & 0,087 & 126 \\
\hline & 5 & 3 & 0,27 & 0,28 & 0,275 & 0,091 & 130 \\
\hline & 6 & 4 & 0,35 & 0,37 & 0,36 & 0,09 & 128 \\
\hline & $7 *$ & 6 & 0,52 & $0,5 / 4$ & $\mathbf{0 , 5 3}$ & 0,088 & 126 \\
\hline & 8 & 10 & 0,92 & 0,90 & 0,91 & 0,091 & 130 \\
\hline & 9 & 15 & 1,30 & 1,32 & 1,31 & 0,087 & 130 \\
\hline & 10 & 9 & 0,81 & 0,81 & 0,823 & 0,092 & 128 \\
\hline \multirow[t]{8}{*}{$0,5 \%$} & 1 & $\frac{3}{4}$ & 0,10 & 0,10 & 0,10 & 0,13 & 120 \\
\hline & 2 & 2 & 0,29 & 0,32 & 0,305 & 0,153 & 126 \\
\hline & 3 & 4 & 0,59 & 0,61 & 0,60 & 0,15 & 128 \\
\hline & l. & $2 \frac{1}{2}$ & 0,39 & 0,37 & 0,38 & 0,152 & 130 \\
\hline & $\breve{b *}^{*}$ & 4 & 0,56 & 0,56 & 0,56 & 0,14 & 125 \\
\hline & 6 & 8 & 1,19 & 1,17 & 1,18 & 0,147 & 125 \\
\hline & 7 & 8 & 1,21 & 1,23 & 1,22 & $0,1: 33$ & 130 \\
\hline & 8 & 3 & $0,4 \mathbf{z}$ & 0,46 & 0,455 & 0,151 & 130 \\
\hline \multirow[t]{8}{*}{$1 \%$} & 1 & 2 & 0,16 & $0,1 \overline{6}$ & 0,16 & $0, \overline{3}^{2}$ & 124 \\
\hline & 2 & $\frac{1}{2}$ & 0,18 & 0,16 & 0,17 & 0,34 & 130 \\
\hline & 3 & $\frac{3}{4}$ & 0,20 & 0,20 & 0,20 & 0,28 & 120 \\
\hline & 4 & $3 \frac{1}{2}$ & 0,96 & 0,96 & 0,96 & 0,27 & 120 \\
\hline & $5 *$ & 2 & 0,66 & 0,67 & 0,665 & 0,335 & 130 \\
\hline & 6 & $1 \frac{1}{2}$ & 0,49 & 0,52 & 0,505 & 0,336 & 132 \\
\hline & 7 & 4 & 1,32 & 1,30 & 1,31 & 0,327 & 126 \\
\hline & 8 & 9 & 2,97 & 2,93 & 2,95 & 0,328 & 128 \\
\hline \multirow[t]{6}{*}{$2 \%$} & 1 & 1 & 0,51 & 0,53 & 0,52 & 0,52 & 120 \\
\hline & 2 & 1 & 0,54 & 0,56 & 0,35 & $0, \mathbf{5 5}$ & 120 \\
\hline & 3 & 1 & 0,57 & $0,5 \ddot{~}$ & 0,56 & 0,56 & $12 !$ \\
\hline & $4^{*}$ & $1 \frac{1}{2}$ & $0,8 \ddot{3}$ & $0,80 ̈$ & 0,85 & 0,56 & $12 \ddot{3}$ \\
\hline & 5 & $1 \frac{1}{4}$ & 0,70 & 0,68 & 0,69 & 0,55 & 125 \\
\hline & 6 & $2 \frac{1}{2}$ & 1,52 & $1, \breve{3} / 4$ & 1,53 & 0,61 & 128 \\
\hline
\end{tabular}




$\begin{array}{cccccccc}\text { Untersättigung: } & \text { Nr. } & t & v_{100} & v_{010} & \text { Mittel } & V_{100} & \text { T.Z. } \\ 4 \% & 1 & \frac{1}{2} & 0,58 & 0,60 & 0,59 & 1,18 & 128 \\ & 2 & \frac{1}{2} & 0,54 & 0,56 & 0,55 & 1,10 & 126 \\ & 3 & \frac{1}{2} & 0,56 & 0,54 & 0,55 & 1,10 & 125 \\ & 4 * & 1 & 1,08 & 1,10 & 1,09 & 1,09 & 126 \\ & 5 & 1 & 1,06 & 1,08 & 1,07 & 1,07 & 120 \\ & 6 & 1 & 1,08 & 1,04 & 1,06 & 1,06 & 124\end{array}$

Tabelle XV.

Mittlere Verschiebungsgeschwindigkeiten bei verschiedenen Untersättigungsgraden am Ausgangskörper $\{100\}$.

$\begin{array}{cccccc}\text { Untersăttigung in \%: } & 0,25 & 0,5 & 1 & 2 & 4 \\ V_{W} & 0,082 & 0,13 & - & - & - \\ V_{100} & 0,089 & 0,147 & 0,318 & 0,370 & 1,100 \\ V_{h k 0} & 0,106 & 0,157 & 0,325 & 0,584 & 1,168 \\ \left(\frac{h}{k} \text { in } h k 0\right) & 22 & 29 & 39 & 48 & 59 \\ V_{h k k} & 0,108 & 0,176 & 0,354 & 0,607 & 1,175 \\ \left(\frac{h}{k} \text { in } h k k\right) & 15 & 16 & 19 & 24 & 49\end{array}$

Die Tabellen XIV und XV lassen deutlich eine Abbängigkeit der Auflösungsgeschwindigkeit von dem Untersättigungsgrade der Lösung erkennen. Die Tabelle XV enthält die nach den Formeln IV und $V$ ermittelten Verschiebungsgeschwindigkeiten der Pyramidenwürfel- und Ikositetraëderflächen. Die Würfelfläche besitzt die kleinste, die Pyramidenwürfelflächen eine etwas größere und die Ikositetraëderflächen die größte Verschiebungsgeschwindigkeit. Diesem Resultat entspricht auch das bei dem Auflösungsvorgang beobachtete Verdrängtwerden des Würfels durch den Pyramidenwürfel einerseits und des letzteren durch das lkositetraëder andererseits. (In der Tabelle $\mathrm{XV}$ bedeuten $V_{W}$ die mittlere Verschiebungsgeschwindigkeit der Würfelfläche, $V_{100}$ die der vierzähligen Ecke.)

Die Auflösungsgeschwindigkeiten der Würfel- und Rhombendodekaëderflächen am Ausgangskörper $\{100\} \cdot\{110\}$.

Die Verschiebungsgeschwindigkeit der Rhombendodekaëderfläche läßt sich während des ganzen Auflösungsprozesses verfolgen, weil diese Fläche nicht verschwindet, während die Würfelflächen durch Ikositetraëderflächen verdrängt werden. Die Auflösungsgeschwindigkeit der Würfelfläche konnte nicht ermittelt werden, daher wurde auch hier wiederum die Verschiebungsgeschwindigkeit der vierzähligen Ecken gemessen und mit $v_{100}$ bezeichnet. Die Auflüsungsgeschwindigkeit der Ikositetraëderflächen läßt sich nach der Seite 316 erwähnten Formel IV berechnen; für $a$ wird die halbe Distanz 
Über die Auflösung von Chlornatriumkrystallen in harnstoff haltigen Lösungen. 319

der Rhombendodekaëderflächen eingesetzt, de an diesem Ausgangskörper die Ikositetraëderflächen die Kombinationskanten der Würfel- und Rhombendodekaëderflächen tangieren.

Tabelle XVI.

Die Verschiebungsgeschwindigkeiten der dem Würfel vicinalen Ikositetraëderflächen und der Rhombendodekaëderflächen bei verschiedenen Untersättigungsgraden.

\begin{tabular}{|c|c|c|c|c|c|c|c|c|}
\hline $\begin{array}{c}\text { Unter- } \\
\text { sättigung }\end{array}$ & Nr. & $t$ & $v_{100}$ & $v_{110}$ & $\frac{v_{1 n 0}}{v_{110}}$ & $V_{100}$ & $V_{110}$ & T.Z. \\
\hline \multirow[t]{7}{*}{$0,25 \%$} & 1 & 1 & 0,06 & 0,08 & 0,7500 & 0,060 & 0,080 & 130 \\
\hline & 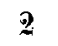 & 2 & 0,11 & $0,1 \ddot{3}$ & 0,7333 & 0,0503 & $0,0 \% 3$ & 125 \\
\hline & 3 & $9 \frac{1}{2}$ & 0,14 & 0,18 & 0,7778 & 0,0306 & $0,0 \tau 2$ & 124 \\
\hline & 4 & 3 & 0,16 & 0,21 & 0,7619 & 0,053 & 0,070 & 120 \\
\hline & $\ddot{3}$ & 2 & 0,11 & 0,14 & 0,7837 & $0,0 \ddot{5}$ & 0,070 & 120 \\
\hline & 6 & 3 & 0,16 & 0,20 & 0,8000 & 0,0503 & 0,067 & 124 \\
\hline & 7 & $3 \frac{1}{2}$ & 0,18 & 0,23 & 0,7826 & 0,0 อ̈2 & 0,066 & 125 \\
\hline \multirow[t]{8}{*}{$0,5 \%$} & 1 & 1 & 0,12 & 0,14 & 0,8371 & 0,12 & 0,14 & 125 \\
\hline & 2 & 1 & 0,13 & 0,17 & 0,8823 & $0,1 \ddot{3}$ & 0,17 & 130 \\
\hline & 3 & $1 \frac{1}{2}$ & 0,21 & 0,24 & 0,8750 & 0,14 & 0,16 & 130 \\
\hline & 4 & 2 & 0,30 & 0,32 & $0,937 \ddot{z}$ & 0,15 & 0,16 & 128 \\
\hline & $\ddot{\partial}$ & 1 & $0,1 \ddot{3}$ & 0,16 & 0,9375 & $0,1 \ddot{~}$ & 0,16 & 128 \\
\hline & 6 & 4 & 0,64 & 0,66 & 0,9697 & 0,16 & 0,163 & 126 \\
\hline & $\tau$ & 4 & 0,60 & 0,62 & 0,9677 & $0,1 \ddot{j}$ & $0,1 \ddot{3} 3$ & 124 \\
\hline & 8 & 3 & 0,46 & 0,48 & 0,9583 & $0,1 \check{3}$ & 0,16 & 130 \\
\hline \multirow[t]{8}{*}{$1 \%$} & 1 & $\frac{1}{2}$ & 0,49 & 0,20 & 0,9 วั00 & 0,38 & 0,40 & 130 \\
\hline & 2 & $\frac{1}{2}$ & 0,17 & 0,18 & 0,9446 & 0,34 & 0,36 & 130 \\
\hline & 3 & $\frac{1}{2}$ & 0,16 & 0,16 & 1,0000 & 0,32 & 0,32 & 128 \\
\hline & 4 & 1 & 0,33 & 0,35 & 0,9428 & 0,33 & 0,35 & 130 \\
\hline & $\ddot{j}$ & 2 & 0,66 & 0,67 & 0,9851 & 0,33 & 0,335 & 130 \\
\hline & 6 & 2 & 0,64 & 0,64 & 1,0000 & 0,32 & 0,32 & 126 \\
\hline & 7 & 2 & 0,62 & 0,61 & 1,0160 & 0,31 & 0,305 & 126 \\
\hline & 8 & 2 & 0,60 & 0,59 & 1,0170 & 0,30 & 0,295 & 125 \\
\hline \multirow[t]{6}{*}{$2 \%$} & 1 & 1 & 0,61 & 0,59 & 1,034 & 0,61 & 0,59 & 130 \\
\hline & 2 & 2 & 1,10 & 1,08 & 1,019 & 0, อ̈5 & 0,54 & 122 \\
\hline & 3 & 1 & 0,56 & $0, \ddot{34}$ & 1,037 & 0,56 & 0,54 & 120 \\
\hline & 4 & 2 & 1,24 & 1,20 & 1,033 & 0,62 & 0,60 & 130 \\
\hline & $\ddot{\jmath}$ & 2 & 1,22 & 1,20 & 1,017 & 0,61 & 0,60 & 128 \\
\hline & 6 & $1 \frac{1}{2}$ & 0,96 & 0,93 & 1,032 & 0,64 & 0,62 & 130 \\
\hline \multirow[t]{5}{*}{$4 \%$} & 1 & 1 & 1,03 & 1,02 & 1,010 & 1,03 & 1,02 & 125 \\
\hline & 2 & 1 & $1,10 \ddot{0}$ & 1,10 & 1,045 & 1,15 & 1,10 & 130 \\
\hline & 3 & 1 & 1,20 & 1,12 & 1,071 & 1,20 & 1,12 & 130 \\
\hline & 4 & 1 & 1,27 & 1,24 & 1,025 & 1,27 & 1,21 & 124 \\
\hline & 5 & 1 & 1,26 & 1,20 & 1,050 & 1,26 & 1,20 & 126 \\
\hline
\end{tabular}


Tabelle XVII.

Mittlere Verschiebungsgeschwindigkeiten bei verschiedenen lintersättigungsgraden am Ausgangskörper $\{100\} \cdot\{110\}$.

$\begin{array}{cccccc}\text { Untersättigung in \% } & 0,23 & 0,5 & 1 & 2 & 4 \\ V_{100} & 0,055 & 0,146 & 0,329 & 0,60 & 1,18 \\ V_{110} & 0,071 & 0,1309 & 0,336 & 0,38 & 1,14 \\ V_{h k i} & 0,087 & 0,189 & 0,350 & 0,62 & 1,22 \\ \left(\frac{h}{k} \text { in } h k k\right) & 13 \frac{1}{2} & 13 \frac{1}{2} & 33 & 42 & 58 \\ \frac{V_{100}}{V_{110}} & 0,7702 & 0,9206 & 0,9819 & 1,0287 & 1,0403 \\ \frac{V_{h k k}}{V_{110}} & 1,22034 & 1,1887 & 1,0417 & 1,0333 & 1,0339\end{array}$

Die Rhombendodekaëderflächen besitzen bei geringer Untersättigung eine größere Auflösungsgeschwindigkeit als die dem Würfel vicinalen Ikositetraëderflächen, welche ihrerseits wiederum sich schneller auflösen als die Würfelflächen. Die berechneten Werte für die Verschiebungsgeschwindigkeit bestimmter am Endkörper der Auflösung auftretenden Ịkositetraëderflächen sind höher als die für die Rhombendodekaëderflächen gemessenen Mittelwerte. Die Unterschiede in den Auflösungsgeschwindigkeiten der betrachteten Flächen werden bei 1 proz. und mehr als 1 proz. Untersättigung gleich Null. Für die Rhombendodekaëderfläche gilt der Satz, daß jede Fläche unter konstanten Bedingungen eine konstante Verschiebungsgeschwindigkeit besitzt.

Die Auflösungsgeschwindigkeiten der Würfel- und Oktaëderflächen am Ausgangskörper $\{100\} \cdot\{111\}$.

Die Verschiebungsgeschwindigkeit der Oktaëderfläche konnte ebenfalls gut verfolgt werden, da sie nicht so schnell von den Ikositetraëderflächen verdrängt wird wie die Würfelfläche. Die Verschiebungsgeschwindigkeit der Würfelfläche ließ sich an diesern Ausgangskörper nicht ermitteln. Es wurde wiederum die Verschiebung der vierzähligen Ecken gemessen $\left(=v_{100}\right)$.

$$
\text { Tabelle XVIII. }
$$

Die Verschiebungsgeschwindigkeiten der dem Würfel vicinalen Ikositetraëderflächen und der Oktaëderflächen beí verschiedenen Untersättigungsgraden.

\begin{tabular}{cccccccccc}
$\begin{array}{c}\text { Unter- } \\
\text { sättigung }\end{array}$ & Nr. & $t$ & $v_{100}$ & $v_{111}$ & $v_{1 \mathrm{~T} 1}$ & $\frac{v_{100}}{v_{111}}$ & $V_{100}$ & $V_{111}$ & T.Z. \\
$0,25 \%$ & 1 & 1 & 0,12 & 0,07 & 0,06 & 1,846 & 0,120 & $0,06 \ddot{3}$ & 130 \\
& 2 & 2 & 0,16 & 0,08 & 0,10 & 1,778 & 0,080 & $0,04: 3$ & 130 \\
& 3 & 3 & 0,22 & 0,13 & 0,11 & 1,833 & 0,073 & 0,040 & 126 \\
& 4 & 3 & 0,23 & 0,12 & 0,13 & 1,840 & $0,07 \tau$ & 0,043 & 128 \\
& 3 & 4 & 0,30 & 0,16 & 0,17 & 1,818 & 0,073 & 0,041 & 128 \\
6 & 8 & 0,64 & 0,36 & 0,35 & 1,803 & 0,080 & 0,045 & 130 \\
& 7 & 10 & 0,82 & 0,403 & 0,47 & 1,782 & 0,082 & 0,046 & 130 \\
\hline
\end{tabular}


Über die Auflösung von Chlornatriumkrystallen in harnstofrhaltigen Lösungen. 321

\begin{tabular}{|c|c|c|c|c|c|c|c|c|c|}
\hline $\begin{array}{c}\text { Unter- } \\
\text { sáttigung }\end{array}$ & Nr. & $t$ & $v_{100}$ & $v_{111}$ & $v_{1 \mathrm{TI}}$ & $\frac{v_{100}}{v_{111}}$ & $\mathrm{~V}_{100}$ & $V_{111}$ & \\
\hline \multirow[t]{6}{*}{$0, \ddot{3} \%$} & 1 & 1 & 0,19 & 0,13 & 0,11 & 1,583 & 0,19 & 0,120 & \\
\hline & 2 & $1 \frac{1}{2}$ & 0,21 & 0,10 & 0,16 & $1,61: 3$ & $0,1 / 4$ & 0,086 & \\
\hline & 3 & 1 & 0,14 & 0,09 & 0,08 & $1,64.7$ & $0,1 / 4$ & 0,083 & \\
\hline & 4 & $\ddot{b}$ & $0, \pi \ddot{3}$ & 0,13 & $0,4 \ddot{3}$ & 1,667 & $0,1 \ddot{3}$ & 0,090 & \\
\hline & $\ddot{3}$ & 2 & $0,3: 3$ & 0,21 & 0,21 & 1,571 & $0,16 \ddot{3}$ & 0,103 & \\
\hline & 6 & 1 & 0,17 & 0,10 & 0,11 & 1,619 & 0,17 & $0,10: 3$ & \\
\hline \multirow[t]{9}{*}{$1 \%$} & 1 & 1 & 0,32 & 0,26 & 0,28 & $1,18 \ddot{3}$ & 0,32 & 0,27 & \\
\hline & 2 & 1 & 0,32 & 0,96 & 0,26 & 1,231 & 0,32 & 0,26 & \\
\hline & 3 & 1 & 0,28 & 0,20 & 0,22 & 1,333 & 0,28 & 0,21 & \\
\hline & 4 & 1 & 0,30 & 0,24 & 0,26 & 1,221 & 0,30 & $0,2 \ddot{3}$ & \\
\hline & $\ddot{3}$ & 1 & 0,31 & 0,27 & $0,2 \ddot{3}$ & 1,192 & 0,31 & 0,26 & \\
\hline & 6 & 1 & 0,31 & 0,23 & 0,23 & $1,3.18$ & 0,31 & 0,23 & \\
\hline & 7 & 2 & 0,62 & 0,47 & 0,46 & 1,319 & 0,31 & 0,24 & \\
\hline & 8 & 3 & 0,99 & 0,73 & $0,7 \ddot{3}$ & 1,320 & 0,33 & 0,233 & \\
\hline & 9 & $3 \frac{1}{9}$ & $1,0: 3$ & 0,76 & 0,78 & 1,364 & 0,30 & 0,22 & \\
\hline \multirow[t]{9}{*}{$2 \%$} & 1 & $\frac{1}{2}$ & 0,29 & 0,28 & - & 1,036 & 0,58 & 0,̈̈6 & \\
\hline & 2 & $\frac{5}{12}$ & 0,22 & 0,20 & - & 1,100 & $0, \ddot{3} 3$ & 0,48 & \\
\hline & 3 & $\frac{1}{2}$ & 0,28 & 0,27 & 一 & 1,037 & 0,56 & 0,34 & \\
\hline & 4 & 1 & $0, \ddot{3} 4$ & $0, \ddot{00}$ & - & 1,080 & 0,54 & 0,50 & \\
\hline & $\ddot{b}$ & 2 & 1,06 & 1,02 & - & 1,039 & 0,53 & $0, \ddot{31}$ & \\
\hline & 6 & 1 & 0,60 & $0, \ddot{37}$ & 一 & 1,053 & 0,60 & 0,37 & \\
\hline & 7 & $\frac{1}{2}$ & 0,34 & 0,32 & - & 1,063 & 0,68 & 0,64 & \\
\hline & 8 & 1 & 0,34 & 0, ̈̈2 & 一 & 1,038 & $0, \$ 4$ & $0, \breve{52} 2$ & \\
\hline & 9 & 2 & 1,28 & 1,24 & - & 1,032 & 0,64 & 0,62 & 13 \\
\hline \multirow[t]{6}{*}{$4 \%$} & 1 & 1 & 0,98 & 0,96 & 0,96 & 1,021 & 0,98 & 0,96 & 12 \\
\hline & 2 & 2 & 2,20 & 2,13 & 2,13 & 1,028 & 1,10 & 1,07 & \\
\hline & 3 & 1 & 1,09 & $1,0 \ddot{3}$ & 1,07 & 1,028 & 1,09 & 1,06 & 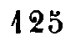 \\
\hline & 4 & 1 & 1,20 & 1,18 & 1,16 & 1,026 & 1,20 & 1,17 & 13 \\
\hline & 5 & 2 & 2,42 & 2,35 & 2,37 & 1,023 & 1,21 & 1,18 & 13 \\
\hline & 6 & 4 & 4,32 & 4,23 & 4,25 & 1,019 & 1,08 & 1,06 & \\
\hline
\end{tabular}

Tabelle XIX.

Mittlere Verschiebungsgeschwindigkeiten bei verschiedenen Untersättigungsgraden am Ausgangskörper $\{100\} \cdot\{11\}$.

\begin{tabular}{cccccc} 
Untersättigung in \% & 0,25 & 0,5 & 1 & 2 & 4 \\
$V_{100}$ & 0,084 & 0,159 & 0,309 & 0,587 & 1,111 \\
$V_{111}$ & 0,046 & 0,098 & 0,243 & 0,549 & 1,083 \\
$V_{100}$ & 1,814 & 1,617 & 1,280 & 1,042 & 1,023 \\
\hline$V_{111}$ & & & & &
\end{tabular}

Groth u. Kaiser, Zeitachrift f. Krystellogr. LIV. 
Die Unterschiede in den Auflösungsgeschwindigkeiten der dem Würfel vicinalen Ikositetraëderflächen und der Oktaëderflächen nebmen mit steigender Untersättigung allmählich ab. Innerhalb eines bestimmten Untersättigungsgrades ist die Auflüsungsgeschwindigkeit sowohl für die dem Würfel vicinalen Ikositetraëderflächen wie für die Oktaëderflächen konstant.

Ein Vergleich der bei den Versuchen über die Auflösungsgeschwindigkeit in verschieden untersättigten $5 \%$ Harnstoff führenden Kochsalzlösungen erhaltenen Resultate läßt eine deutliche Abhängigkeit der Auflüsungsgeschwindigkeit von dem Untersättigungsgrade erkennen. Je höher die Untersättigung, desto größer die Verschiebungsgeschwindigkeit. Die Verschiebungsgeschwindigkeit der dem Würfel vicinalen Flächen an den drei verschiedenen Ausgangskörpern gibt bei gleicher Untersättigung nahezu gleiche Resultate; auch die für bestimmte Ikositetraëderflächen berechneten Werte zeigen eine gute Übereinstimmung. Noch besser läßt sich diese Erscheinung an den vollkommen ebenbleibenden Rhombendodekaëder- und Oktaëderflächen beobachten. Es gilt also der Satz: s.Jede Fläche besitzt unter bestimmten Bedingungen eine bestimmte, von ihrer Größe und Umgrenzung unabhängige Verschiebungsgeschwindigkeit. \&

Die Unterschiede in der Auflüsungsgeschwindigkeit verschiedenartiger Krystallflächen treten besonders bei geringen Untersättigungen hervor, nehmen aber mit steigender Untersättigung schnell ab. Für die Rhombendodekaëderfläche wird der Unterschied gegen die dem Würfel vicinalen Ikositetraëderflächen bei ungefähr $1 \%$ Untersättigung gleich Null, für die Oktaëderfläche zeigen sich Unterschiede noch bei 4\% Untersättigung. Von den betrachteten Flächen besitzt die Oktaëderfläche die kleinste, die dem Würfel vicinalen Pyramidenwürfelflächen eine etwas größere Verschiebungsgeschwindigkeit, während die der Würfelfäche, die nur bei 0,25 und $0,3 \%$ Untersättigung ermittelt werden konnte, einen Zwischenwert einnimmt. Die $\{h k 0\}$ wiederum werden an Schnelligkeit von den Ikositetraëder- und Rhombendodekaëderflächen übertroffen. Dieser Reihenfolge entspricht auch das Auftreten der Pyramidenwürfel- und lkositetraëderflächen an den würfelförmigen Ausgangskörpern, das Verdrängtwerden der Würfel- und Oktaëderflächen von den Ikositetraëderflächen am Ausgangskörper $\{100\} \cdot\{111\}$. Die Rhombendodekaëderfläche, die an Größe der Verschiebungsgeschwindigkeit der Ikositetraëderfläche sehr nahe kommt, konkurriert am Ausgangskörper $\{100\} \cdot\{110\}$ infolge der geringen Urpunktsdistanz mit Erfolg gegen die Ikositetraëderflächen. Besitzt dagegen die Rhombendodekaëderfläche eine im Verhältnis zu ihrer Auflüsungsgeschwindigkeit zu große Urpunktsdistanz, so wird sie trotz ihrer relativ großen Verschiebungsgeschwindigkeit nicht reell. Bei kugelförmigen Ausgangskörpern hesitzen alle nur müglichen Flächen die gleiche Urpunktsdistanz. In 0,25-1\% untersättigten Lösungen ist der Endkörper der Auflüsung ein bloßes Ikositretraëder; bei 
Über die Auflösung von Chlornatriumkrystallen in harnstoffhaltigen Lösungen. 323

2 und $4 \%$ Untersättigung verrunden die zweizähligen Ecken, indem hier nicht nur die Rhombendodekaëderfächen, sondern auch eine ganze Reihe der ihnen benachbarten Pyramidenwürfelflächen am Endkörper ausgebildet sind.

b) Die Auflösungsgeschwindigkeiten der Würfel-, Rhombendodekaëder- und Oktaëderflächen bei 1 proz. Untersättigung in Kochsalzlösungen mit verschieden-prozentigem Harnstoffzusatz.

Die Auflösungsgeschwindigkeiten wurden in 10, 20, 40,60 und $80 \%$ Harnstoff führenden Kochsalzlösungen ermittelt, die um $1 \%$ untersättigt waren. Es gelten hier dieselben Lösungen, Versuchsanordnungen und Bedingungen wie die für die Auflösungskörper angewendeten. Bei der Messung der Verschiebungsgeschwindigkeiten wurde wie vorher verfahren.

\section{Ausgangskörper $\{100\}$.}

Die Verschiebungsgeschwindigkeit der Würfelfläche konnte nicht ermittelt werden, da sie bereits nach dem ersten Versuch von ihr vicinalen Pyramidenwürfelflächen verdrängt war. Es wurde wiederum die Verschiebungsgeschwindigkeit der vierzähligen Ecken ermittelt und diese mit $v_{100}$ bzw. $v_{010}$ bezeichnet.

\section{Tabelle XX.}

Die Verschiebungsgeschwindigkeit der dem Würfel vicinalen Flächen bei verschiedenprozentigem Harnstofrzusatz.

\begin{tabular}{|c|c|c|c|c|c|c|c|}
\hline Harnstoffzusatz & $\mathrm{Nr}$. & $t$ & $v_{100}$ & $v_{010}$ & Mittel & $V_{100}$ & T.Z. \\
\hline \multirow[t]{8}{*}{$10 \%$} & 1 & $\frac{1}{2}$ & 0,14 & 0,16 & 0,13 & 0,30 & 130 \\
\hline & 2 & 1 & 0,30 & 0,32 & 0,31 & 0,31 & 126 \\
\hline & 3 & 2 & 0,64 & 0,64 & 0,64 & 0,32 & 130 \\
\hline & 4* & 1 & 0,31 & 0,29 & 0,30 & 0,30 & 130 \\
\hline & $\ddot{3}$ & 3 & 1,01 & 1,06 & 1,03 & $0,3 \ddot{0}$ & 130 \\
\hline & 6 & 4 & $1,3 \pi$ & 1,33 & 1,36 & 0,34 & 128 \\
\hline & $\tau$ & 6 & 1,96 & 2,00 & 1,98 & 0,33 & 130 \\
\hline & 8 & $\ddot{3}$ & 1,62 & $1, \ddot{38} 8$ & 1,60 & 0,32 & 127 \\
\hline \multirow[t]{8}{*}{$20 \%$} & 1 & $\frac{1}{2}$ & 0,16 & 0,18 & 0,17 & 0,34 & 130 \\
\hline & 2 & $\frac{1}{2}$ & 0,17 & 0,13 & 0,16 & 0,32 & 130 \\
\hline & 3 & $\frac{1}{2}$ & $0,1 \ddot{3}$ & 0,15 & 0,15 & 0,30 & 126 \\
\hline & 4 & 2 & $0,6 \ddot{3}$ & 0,67 & 0,66 & 0,33 & 128 \\
\hline & $\ddot{b}$ & 2 & $0,6 \ddot{3}$ & 0,63 & 0,64 & 0,32 & 130 \\
\hline & $6^{*}$ & $2 \frac{1}{2}$ & $0, \pi 3$ & $0,7 \ddot{3}$ & 0,74 & 0,30 & 123 \\
\hline & 7 & 4 & 1,17 & $1,1: 3$ & 1,16 & 0,29 & 125 \\
\hline & 8 & $\mathfrak{5}$ & 1,506 & 1,54 & 1,55 & 0,31 & 128 \\
\hline
\end{tabular}




\begin{tabular}{|c|c|c|c|c|c|c|c|}
\hline Harnstoffzusatz & Nr. & $t$ & $v_{100}$ & $v_{010}$ & Miltel & $V_{100}$ & T.Z. \\
\hline \multirow[t]{8}{*}{$40 \%$} & 1 & $\frac{1}{2}$ & 0,17 & 0,16 & 0,163 & 0,33 & 128 \\
\hline & 2 & $\frac{3}{4}$ & 0,23 & 0,20 & 0,24 & 0,32 & 126 \\
\hline & 3 & 2 & $0, \ddot{54}$ & 0,34 & $0, \ddot{3} 4$ & 0,27 & 120 \\
\hline & 4 & 2 & 0,57 & 0,39 & $0, ; 38$ & 0,29 & 124 \\
\hline & 5 & 3 & 0,95 & $0,9 \ddot{3}$ & $0,9 \ddot{~}$ & 0,32 & 128 \\
\hline & $6^{*}$ & 7 & 2,19 & 2,17 & 2,18 & 0,31 & 130 \\
\hline & 7 & 2 & 0,60 & 0,60 & 0,60 & 0,30 & 125 \\
\hline & 8 & 6 & 1,67 & 1,69 & 1,68 & 0,28 & 120 \\
\hline \multirow[t]{8}{*}{$60 \%$} & 1 & $\frac{1}{2}$ & 0,09 & 0,07 & 0,08 & 0,16 & 130 \\
\hline & 2 & 1 & 0,15 & $0,1 \ddot{3}$ & $0,13 ̈$ & $0,15 ั$ & 126 \\
\hline & 3 & 5 & 0,74 & 0,76 & $0,7 \ddot{b}$ & 0,15 & 126 \\
\hline & 4 & 3 & 0,53 & 0,49 & 0,301 & 0,17 & 130 \\
\hline & $5 *$ & 4 & 0,64 & 0,62 & 0,63 & 0,16 & 130 \\
\hline & 6 & 4 & 0,65 & 0,63 & 0,64 & 0,16 & 130 \\
\hline & 7 & 4 & 0,60 & 0,62 & 0,61 & 0,15 & 126 \\
\hline & 8 & 7 & 1,09 & 1,13 & 1,11 & 0,16 & 130 \\
\hline \multirow[t]{10}{*}{$80 \%$} & 1 & $\frac{1}{2}$ & 0,07 & 0,09 & 0,08 & 0,16 & 130 \\
\hline & 2 & $\frac{3}{4}$ & 0,12 & 0,12 & 0,12 & 0,16 & 130 \\
\hline & 3 & 2 & 0,29 & 0,27 & 0,28 & 0,14 & 123 \\
\hline & 4 & 3 & 0,46 & 0,44 & $0,4 \vec{z}$ & $0,1 \ddot{3}$ & 126 \\
\hline & $\breve{5}$ & 2 & 0,27 & 0,29 & 0,28 & 0,14 & 124 \\
\hline & 6 & 5 & 0,74 & 0,72 & 0,73 & 0,1 ठ̈ & 125 \\
\hline & $7 *$ & 4 & 0,56 & 0,54 & 0,55 & 0,14 & 120 \\
\hline & 8 & 5 & 0,74 & 0,76 & 0,7 อ̆ & 0,15 & 125 \\
\hline & 9 & 10 & 1,53 & 1,31 & 1,52 & 0,15 & 126 \\
\hline & 10 & 11 & 1,76 & 1,80 & 1,78 & 0,16 & 130 \\
\hline
\end{tabular}

Tabelle XXI.

Mittlere Verschiebungsgeschwindigkeit der dem Würfel vicinalen Pyramidenwürfelund Ikositetraëderflächen bei verschieden-prozentigem Harnstoffzusatz.

Harnstoffzusatz

in $\%$

$V_{100}$

5

0,318

10

$V_{h k 0}$

0,325

0,321

46

0,345
0,314

0,348

56

10

0,302

0,336

28

0,322
60

0,157 0,177

29

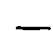

80

0,150 0,163

$28 \frac{1}{2}$

$$
\left(\frac{h}{k} \text { in } h k k\right) \quad 19 \quad 42 \quad 46
$$

Die Auflösungsgeschwindigkeit der dem Würfel vicinalen Flăchen ist für verschiedenen Harnstoffzusatz bei 1 proz. Untersättigung innerhalb der 
Über die Auflösung von Chlornatriumkrystallen in harnstoffhaltigen Lösungen. 325 .

Fehlergrenzen gleich. Die Werte, die sich auf Harnstoff-Kochsalzlösungen von 60 und $80 \%$ Harnstoffzusatz beziehen, sind aus Lösungen ermittelt worden, welche aus nur $6 \mathrm{l}$ reiner gesättigter Chlornatriumlösung durch Zusatz von Harnstoff und $\mathrm{NaCl}$ gewonnen waren. Sie ergaben untereinander gleiche, aber nur halb so große Verschiebungsgeschwindigkeiten als die Werte bei 10,20 und $4.0 \%$ Harnstoffzusatz. Die Verschiebungsgeschwindigkeit der dem Würfel benachbarten Pyramidenwürfel- und Ikositetraëderflächen wurde nach den angegebenen Formeln IV und V (S. 316) berechnet. Es zeigt sich auch hier wiederum gemäß den bei den Auflösungserscheinungen gemachten Beobachtungen, daß die zuletzt an dem Auflösungskörper auftretenden steilsten Pyramidenwïrfelfächen eine größere Verschiebungsgeschwindigkeit besitzen als die zuerst auftretenden flacheren, die jedoch kleiner ist als die der $\{h k k\}$, die schließlich allein am Endkörper ausgebildet sind. Die Verschiebungsgeschwindigkeit der Ikositetraëderflächen bei $10-80 \%$ Harnstoffzusatz konnte nicht berechnet werden, da sich keine Messungen der Neigungswinkel bewerkstelligen ließen.

$$
\text { Ausgangskürper }\{100\} \cdot\{110\} \text {. }
$$

An diesem Ausgangskörper wurde wiederum die Verschiebungsgeschwindigkeit der vierzähligen Ecke ermittelt, da die Würfelfläche während des Auflösungsvorganges nicht erhalten blieb. Dagegen ließ sich die Verschiebung der glatt- und ebenbleibenden Rhombendodekaëderflächen gut messen.

\section{Tabelle XXII.}

Die Verschiebungsgeschwindigkeit der dem Würfel vicinalen Ikositetraëderflächen und der Rhombendodekaëderflächen bei verschieden-prozentigem Harnstoffzusatz.

\begin{tabular}{|c|c|c|c|c|c|c|c|c|}
\hline Harnstođzusatz & Nr. & $t$ & $v_{100}$ & $v_{110}$ & $\frac{v_{100}}{v_{110}}$ & $V_{100}$ & $V_{110}$ & T.Z. \\
\hline \multirow[t]{6}{*}{$10 \%$} & 1 & $\frac{1}{2}$ & 0,16 & 0,18 & 0,8889 & 0,32 & 0,36 & 130 \\
\hline & 2 & $\frac{1}{2}$ & 0,17 & 0,18 & 0,9445 & 0,31 & 0,36 & 130 \\
\hline & 3 & $i$ & 0,30 & 0,32 & 0,9375 & 0,30 & 0,32 & 128 \\
\hline & 4 & 1 & 0,3 : & $0,3 i$ & 0,9189 & 0,34 & 0,37 & 132 \\
\hline & $\ddot{j}$ & 2 & 0,68 & 0,68 & 1,0000 & 0,34 & 0,34 & 134 \\
\hline & 6 & 3 & 0,96 & 0,99 & 0,9697 & 0,32 & 0,33 & 130 \\
\hline \multirow[t]{7}{*}{$20 \%$} & 1 & $\frac{1}{2}$ & 0,20 & 0,20 & 1,0000 & 0,40 & 0,40 & 130 \\
\hline & 2 & $\frac{1}{2}$ & 0,17 & 0,18 & 0,9446 & 0,34 & 0,36 & 130 \\
\hline & 3 & $\frac{1}{2}$ & $0,1 \ddot{3}$ & 0,17 & 0,8823 & 0,30 & $0,3 / 4$ & 128 \\
\hline & 4 & 1 & 0,37 & 0,39 & 0,9487 & 0,37 & 0,39 & 130 \\
\hline & $\ddot{j}$ & 3 & 0,92 & 0,93 & 0,9893 & 0,31 & 0,31 & 126 \\
\hline & 6 & 4 & 1,10 & 1,47 & 0,95024 & $0,3 \ddot{3}$ & 0,37 & 130 \\
\hline & 7 & 3 & 1,09 & $1,1 \ddot{3}$ & 0,9478 & 0,36 & 0,38 & 130 \\
\hline
\end{tabular}




\begin{tabular}{|c|c|c|c|c|c|c|c|c|}
\hline Harnstoffzusatz & Nr. & $t$ & $v_{100}$ & $v_{110}$ & $\frac{v_{100}}{v_{110}}$ & $V_{100}$ & $V_{110}$ & T.Z. \\
\hline \multirow[t]{8}{*}{$40 \%$} & 1 & $\frac{1}{2}$ & $0,1 \ddot{3}$ & 0,18 & 0,8333 & 0,30 & 0,36 & 128 \\
\hline & 2 & 1 & 0,29 & 0,32 & 0,9063 & 0,29 & 0,32 & 126 \\
\hline & 3 & 1 & 0,31 & $0,3 \breve{~}$ & 0,8387 & 0,31 & 0,35 & 127 \\
\hline & 4 & 2 & 0,70 & 0,74 & 0,9459 & $0,3 \check{~}$ & 0,37 & 130 \\
\hline & $\breve{5}$ & 3 & $1,0 \ddot{3}$ & 1,08 & 0,9722 & 0,35 & 0,36 & 132 \\
\hline & 6 & 3 & 1,02 & 1,07 & 0,9533 & 0,34 & 0,36 & 130 \\
\hline & 7 & 2 & 0,64 & 0,68 & 0,9412 & 0,32 & 0,34 & 130 \\
\hline & 8 & 3 & 0,96 & 0,98 & 0,9796 & 0,32 & 0,33 & 130 \\
\hline \multirow[t]{8}{*}{$60 \%$} & 1 & $\frac{1}{2}$ & 0,07 & 0,08 & 0,8750 & 0,14 & 0,16 & 130 \\
\hline & 2 & 1 & $0,1 \ddot{z}$ & 0,16 & 0,9375 & 0,15 & 0,16 & 130 \\
\hline & 3 & 1 & 0,16 & 0,17 & 0,9412 & 0,16 & 0,17 & 130 \\
\hline & 4 & 2 & 0,32 & 0,35 & 0,9143 & 0,16 & 0,175 & 128 \\
\hline & $\mathbf{5}$ & 2 & 0,32 & 0,34 & 0,9412 & 0,16 & 0,17 & 128 \\
\hline & 6 & 2 & 0,33 & 0,37 & 0,8919 & 0,165 & 0,185 & 130 \\
\hline & 7 & 2 & 0,30 & 0,32 & 0,9375 & 0,15 & 0,16 & 126 \\
\hline & 8 & 4 & 0,61 & 0,63 & 0,9682 & 0,15 & 0,158 & 126 \\
\hline \multirow[t]{6}{*}{$80 \%$} & 1 & $\frac{1}{2}$ & 0,09 & 0,10 & 0,9000 & 0,18 & 0,20 & 132 \\
\hline & 2 & 1 & 0,16 & 0,17 & 0,9412 & 0,16 & 0,17 & 130 \\
\hline & 3 & 1 & 0,15 & 0,16 & 0,9375 & $0,1 \breve{~}$ & 0,16 & 128 \\
\hline & 4 & 2 & 0,32 & 0,34 & 0,9412 & 0,16 & 0,17 & 130 \\
\hline & $\mathbf{5}$ & 3 & 0,49 & 0,54 & 0,9074 & 0,16 & 0,18 & 131 \\
\hline & 6 & 5 & 0,81 & 0,88 & 0,9205 & 0,16 & 0,175 & 130 \\
\hline
\end{tabular}

Tabélle XXIII.

Mittlere Verschiebungsgeschwindigkeit der dem Würfel vicinalen Ikositetraëderflächen und der Rhombendodekaëderflächen bei verschieden-prozentigem Harnsloffzusatz.

$\begin{array}{ccccccc}\text { Harnstoffzusatz in } \%: 5 & 10 & 20 & 40 & 60 & 80 \\ \nabla_{100} & 0,329 & 0,327 & 0,347 & 0,322 & 0,155 & 0,162 \\ \nabla_{110} & 0,336 & 0,347 & 0,364 & 0,349 & 0,167 & 0,173 \\ \frac{V_{100}}{\nabla_{110}} & 0,9819 & 0,9432 & 0,9407 & 0,9251 & 0,9258 & 0,9246 \\ \nabla_{h k k} & 0,350 & 0,355 & 0,360 & 0,348 & 0,175 & 0,190 \\ \left(\frac{h}{k} \text { in } h k k\right) & 33 & 41 & 46 & 39 & 40 & 40 \\ \frac{\nabla_{h k k}}{\nabla_{110}} & 1,0417 & 1,0230 & 0,9890 & 1,0000 & 1,0480 & 1,0983\end{array}$


Über die Auflösung von Chlornatriumkrystallen in harnstoff haltigen Lösungen. 327

Tabelle XXIV.

Die Verschiebungsgeschwindigkeit der Rhombendodekaëderflächen bei $80 \%$ Harnstofrzusatz und bei 1 proz. Untersättigung ermittelt an einem modellartigen Rhombendodekaëder.

\begin{tabular}{|c|c|c|c|c|c|c|c|c|c|c|}
\hline $\mathrm{Nr}$. & $t$ & $v_{110}$ & $v_{1 T 0}$ & $v_{011}$ & $v_{0 T_{1}}$ & 101 & $v_{\text {T0 } 1}$ & & $V_{110}$ & \\
\hline 1 & 2 & 03 & 0,36 &, 36 & 0,37 & $0,3 \breve{~}$ & 0,37 & 0,360 & & \\
\hline 2 & 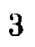 & O & $0, \ddot{b} \ddot{3}$ & 0,33 & Q & & & & & \\
\hline 4 & 3 &, 56 & $0,0 ̈ b$ & $0, \ddot{0} 4$ & $0, \ddot{0} \ddot{3}$ & 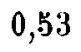 & 0 , & & & 80 \\
\hline 6 & & 0,32 & 0,31 & 0,31 & 0,33 & 0,32 & 0 , & & & \\
\hline 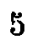 & & 0,7 &, 72 & $0 \div 0$ & 0,71 & 0,70 & 0 & 17 & 0 & \\
\hline & & 0,88 & 0,89 & 0,87 & 0,89 & 0,89 & 0,86 & 0,880 & 0,176 & 133 \\
\hline
\end{tabular}

Die Auflösungsgeschwindigkeiten der dem Würfel vicinalen Ikositetraëderflächen sind nahezu einander gleich und ändern sich bei steigendem Harnstoffzusatz sehr langsam. Die Tabelle XXIV gibt wiederum einen Beweis für den Satz, daß die Verschiebungsgeschwindigkeit einer Fläche unter bestimmten Bedingungen einen von ihrer Größe und Umgrenzung unabhängigen bestimmten Wert hat.

$$
\text { Ausgangskörper }\{100\} \cdot\{111\} \text {. }
$$

Tabelle XXV.

Die Verschiebungsgeschwindigkeiten der dem Würfel vicinalen Ikositetraëderflächen und der Oktaëderflächen bei verschieden-prozentigem Harnstoffzusatz.

\begin{tabular}{|c|c|c|c|c|c|c|c|c|c|}
\hline $\begin{array}{l}\text { Harnstoff- } \\
\text { zusatz }\end{array}$ & Nr. & $t$ & $v_{100}$ & $v_{111}$ & $v_{1 T_{1}}$ & $\frac{v_{100}}{v_{111}}$ & $V_{100}$ & $V_{111}$ & T.Z. \\
\hline \multirow[t]{8}{*}{$10 \%$} & 1 & 1 & 0,34 & 0,25 & 0,27 & 1,3077 & 0,34 & 0,26 & 134 \\
\hline & 2 & 1 & 0,36 & 0,32 & 0,28 & 1,2000 & 0,36 & 0,30 & 134 \\
\hline & 3 & 1 & 0,29 & 0,23 & 0,21 & 1,3182 & 0,29 & 0,22 & 130 \\
\hline & 4 & 1 & 0,30 & 0,22 & 0,26 & 1,2500 & 0,30 & 0,24 & 130 \\
\hline & $\mathbf{5}$ & 2 & 0,64 & 0,48 & 0,46 & 1,3334 & 0,32 & 0,24 & 132 \\
\hline & 6 & 2 & 0,62 & 0,46 & 0,48 & 1,3191 & 0,31 & 0,24 & 130 \\
\hline & 7 & 4 & 1,21 & 0,99 & 1,01 & 1,3043 & 0,30 & 0,23 & 130 \\
\hline & 8 & 8 & 2,53 & 1,89 & 1,87 & 1,3191 & 0,31 & 0,24 & 128 \\
\hline \multirow[t]{9}{*}{$20 \%$} & 1 & $\frac{1}{2}$ & 0,15 & 0,12 & 0,13 & 1,2000 & 0,30 & 0,25 & 130 \\
\hline & 2 & $\frac{1}{2}$ & 0,15 & 0,12 & 0,11 & 1,3043 & 0,30 & 0,23 & 130 \\
\hline & 3 & $\frac{1}{2}$ & 0,14 & 0,10 & 0,11 & 1,3333 & 0,28 & 0,21 & 130 \\
\hline & 4 & 1 & 0,32 & 0,23 & 0,25 & 1,3333 & 0,32 & 0,24 & 32 \\
\hline & $\mathbf{5}$ & 1 & 0,34 & 0,27 & 0,25 & 1,3077 & 0,34 & 0,26 & 135 \\
\hline & 6 & 1 & 0,33 & 0,24 & 0,26 & 1,3200 & 0,33 & 0,25 & 132 \\
\hline & 7 & 2 & 0,62 & 0,48 & 0,46 & 1,3191 & 0,31 & 0,235 & 130 \\
\hline & 8 & 4 & 1,30 & 0,96 & 1,00 & 1,3265 & 0,325 & 0,245 & 132 \\
\hline & 9 & 4 & 1,20 & 0,91 & 0,93 & 1,3043 & 0,30 & 0,23 & 130 \\
\hline
\end{tabular}




\begin{tabular}{|c|c|c|c|c|c|c|c|c|c|}
\hline $\begin{array}{c}\text { Harnstoff- } \\
\text { zusatz }\end{array}$ & Nr. & $t$ & $v_{100}$ & $v_{111}$ & $v_{1 \mathrm{TI}}$ & $\frac{v_{100}}{v_{111}}$ & $V_{100}$ & $V_{111}$ & T.Z. \\
\hline \multirow[t]{6}{*}{$40 \%$} & 1 & 1 & 0,32 & 0,26 & 0,24 & 1,2800 & 0,32 & 0,25 & 130 \\
\hline & 2 & 2 & 0,6 & $0,4.6$ & 0,50 & 1,3334 & 0,32 & 0,24 & 128 \\
\hline & 3 & 2 & 0,60 & 0,43 & $0,4: 3$ & $1,363 \%$ & 0,30 & 0,22 & 126 \\
\hline & 4 & 4 & 1,28 & 0,98 & 0,96 & 1,3334 & 0,32 & 0,24 & 130 \\
\hline & b & 5 & $1, \ddot{3} 6$ & 1,16 & 1,14 & 1,3อ̈6อ̈ & 0,31 & 0,23 & 130 \\
\hline & 6 & 4 & 1,26 & 0,89 & 0,91 & 1,4000 & 0,32 & 0,23 & 132 \\
\hline \multirow[t]{6}{*}{$60 \%$} & 1 & 1 & 0,16 & 0,15 & 0,17 & 1,0000 & 0,160 & 0,160 & 130 \\
\hline & $\mathbf{2}$ & 1 & 0,17 & 0,10 & 0,08 & 1,8889 & 0,170 & 0,090 & 132 \\
\hline & 3 & 1 & 0,16 & 0,09 & 0,08 & 1,6842 & 0,160 & 0,095 & 130 \\
\hline & 4 & 2 & 0,31 & 0,20 & 0,22 & 1,1772 & $0,13 ̋ \mathrm{z}$ & 0,103 & 128 \\
\hline & $\ddot{3}$ & 4 & $0,6 \mathrm{I}$ & 0,43 & 0,12 & $1,43 \ddot{3} 3$ & 0,102 & 0,106 & 126 \\
\hline & 6 & 4 & 0,64 & 0,43 & $0, \not \ddot{3}$ & $1,40040 ّ$ & 0,160 & 0,110 & 130 \\
\hline \multirow[t]{6}{*}{$80 \%$} & 1 & 1 & 0.16 & 0,12 & 0,10 & 1,43.13 & 0,160 & 0,110 & 130 \\
\hline & $\mathbf{2}$ & 1 & 0,17 & 0,11 & 0,10 & 1,6190 & 0,170 & $0,10 \check{ }$ & 130 \\
\hline & 3 & 2 & 0,33 & 0,20 & 0,22 & 1,5714 & 0,163 & 0,103 & 132 \\
\hline & 4 & 4 & $0,6 \ddot{~}$ & 0,42 & 0,40 & $1,0 ̋ 83 ٌ 4$ & 0,162 & 0,102 & 130 \\
\hline & $\ddot{3}$ & $\ddot{b}$ & 0,83 & $0, \ddot{5} 3$ & $0, \ddot{3} 4$ & $1, \ddot{0} 314$ & 0,166 & 0,107 & 130 \\
\hline & 6 & $\ddot{3}$ & 0,8 ä & $0, \breve{\partial ̆}$ & 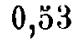 & 1,כั7女1 & 0,170 & 0,108 & 133 \\
\hline
\end{tabular}

Tabelle XXVI.

Mittlere Verschiebungsgeschwindigkeit der dem Würfel vicinalen Ikositetraëderflächen und der Oktaëderflächen bei verschieden-prozentigem Harnstoflzusatz.

$\begin{array}{ccccccc}\text { Harnstoffzusatz in } \%: 5 & 10 & 20 & 40 & 60 & 80 \\ V_{100} & 0,309 & 0,316 & 0,311 & 0,3130 & 0,1393 & 0,16535 \\ V_{111} & 0,243 & 0,245 & 0,239 & 0,233 & 0,111 & 0,106 \\ \frac{V_{100}}{V_{111}} & 1,279 \ddot{3} & 1,2937 & 1,3034 & 1,344 \ddot{3} & 1,4900 & 1,5593\end{array}$

Das Verhältnis der Auflösungsgeschwindigkeiten der dem Würfel vicinalen Ikositetraëderflächen und der Oktaëderflächen nimmt mit steigendem Harnstoffgehalt $\mathrm{zu}$; die ersteren besitzen eine fast konstante Auflösungsgeschwindigkeit, während diejenige der Oktaëderfläche mit steigendem Harnstoffgehalt allmählich abnimmt.

Die bei höherem Harnstoffgehalt ermittelten Auflüsungsgeschwindigkeiten zeigen eine Abhängigkeit der Verschiebungsgeschwindigkeit von dem Lösungsmittel. Während die der Würfelfäche vicinalen Flächen und die Rhombendodekaëderflächen bei steigendem Harnstoffgehalt, aber gleichbleibender Untersättigung eine konstante und untereinander gleiche Verschiebungsgeschwindigkeit $\mathrm{zu}$ besitzen scheinen, nimmt die Verschiebungsgeschwindigkeit der Oktaëderfläche mit steigendem Harnstoffzusatz allmählich ab. Die Pyramidenwürfel- und Ikositetraëderflächen besitzen eine im 
Verhältnis zur Würfelfläche größere Verschiebungsgeschwindigkeit, weshalb sie auch bei der Auflösung an den untersuchten Krystallkörpern reell werden konnten. Das Rhombendodekaëder ist an den Endkörpern der Kugel, die aus 10-20\% Harnstoff führenden Kochsalzlösungen erhalten wurden, neben ejner Reihe von ihm vicinalen Pyramidenwürfelflächen als verrundete Fläche realisiert, während es bei $10-80 \%$ Harnstoffzusatz nicht auftritt. Die Oktaëderflächen sind infolge ihrer geringen Verschiebungsgeschwindigkeit nicht von langer Dauer; sie werden in das virtuelle Reich zurückgedrängt. Die Rhombendodekaëderflächen des Ausgangskörpers $\{100\} \cdot\{1 \cdot 10\}$ bleiben während des ganzen Auflösungsprozesses erhalten, und zwar erstens infolge ihrer geringen anfänglichen Urpunktsdistanz, zweitens, weil ihre Verschiebungsgeschwindigkeit nur ungefähr gleich derjenigen der dem Würfel benachbarten flacheren $\{h k k\}$ ist. Es bestätigte sich wiederum bei diesen Versuchen, daß die Flächen unter bestimmten Bedingungen eine bestimmte, von ihrer Größe und Ujmgrenzung unabhängige Verschiebungsgeschwindigkeit besitzen.

\section{Hauptergebnisse.}

Die Ergebnisse der vorliegenden Cntersuchungen über die Auflösung von Chlornatriumkrystallen in harnstoflhalligen Lösungen lassen sich in folgende Sätze zusammenfassen:

1. Die Form der Auflösungskörper und der Endkörper der Auflösung ist abhängig von dem Untersättigungsgrade des Lösungsmittels.

2. Harnstoffzusatz zu Chlornatriumlösungen bewirkt nicht nur beim Wachstum sondern auch bei der Auflösung eine Formbeeinflussung; diese macht sich in der Form der Auflösungskörper und der Endkörper der Auflüsung geltend.

3. Bei dem Endkörper der Auflösung bilden sich scharfe Ecken an den Polen derjenigen Flächen, welche an dem Endkörper des Wachstums vorherrschen, wenn sich Auflüsung und Wachstum bei gleichem Harnstoffgehalt vollziehen.

1. Bei der Formbeeinflussung durch verschiedenen Harnstoffzusatz scheinen "Schwellenwert (beginnende Beeinflussung) und ,Höhenwert * (maximale Beeinflussung) sowohl für das Wachstum wie für die Auflösung die gleichen Werte zu haben.

3. Bei bestimmtem Harnstoffzusatz und bei bestimmter Untersälligung besitzt jede Fläche während des ganzen Auflösungsprozesses eine konstante Auflösungsgeschwindigkeit.

6. Die Unterschiede in den Auflösungsgeschwindigkeiten verschiedener Flächenarten nehmen mit steigender Untersättigung $a b$.

7. Höherer Harnstoffgehalt bewirkt eine Erhöhung des Unterschiedes der Auflösungsgeschwindigkeiten der dem Würfel vicinalen Ikositetraëderflächen und der Oktaëderflächen. 
8. Der Endkörper der Auflösung zeigte sich in manchen Fällen, wie Johnsen theoretisch voraussah, abhängig von der Form des Ausgangskürpers. So lieferte bei $80 \%$ Harnstoffzusatz und bei 1 proz. Untersättigung ein modellartiges Rhombendodekaëder als Endkörper wieder ein modellartiges Rhombendodekaëder, während unter den gleichen Bedingungen eine Kugel als Endkürper einen Krystallkörper ergab, der einem Hexaëder mit stark gekrümmten Kanten und Flächen glich und dessen vierzählige Ecken Spuren von Ikositetraëderkanten in Form eines kJeinen vierstrahligen Sternchens aufwiesen. Eine Kombination $\{100\} \cdot\{111\}$ ging in einen Endkörper über, der einem lkositetraëder glich, dessen zweizählige Ecken aber von gekrümmten Kanten überspannt wurden, die den Hexaëderkanten benachbart sind. (Vgl. Taf. X, Fig. 21 Rhombendodekaëder, Fig. 20 Endkörper der Auflösung der Kugel und Taf. X, Fig. $1 \ddot{3}$ Endkörper der Auflösung einer Kombination $\{100\} \cdot\{111\}$ bei $80 \%$ Harnstoffzusatz und bei 1 proz. Untersättigung.)

Die vorliegende Arbeit wurde im Mineralogischen Institut der Universität Kiel ausgeführt. Es sei mir auch an dieser Stelle gestattet, dem Direktor desselben, meinem hochverehrten Lehrer, Herrn Prof. Dr. A. Johnsen, der mir die Anregung zu dieser Arbeit gab und mich bei ihrer Ausführung stets in der wohlwollendsten Weise unterstützte, meinen herzlichsten Dank auszusprechen.

Kiel, Mineralogisches Institut und Museum der Universität.

\section{Tafolerklärung.}

(Zu Tafel X.)

Abkürzungen: U. = Untersätligung, H.Z. = Harnstoffzusatz.

Fig. 2-7. Auflösungskörper und Endkörper der Auflösung eines würfelformigen A usgangskörpers (Fig. 1).

Fig. 2-5 bei 0,25 proz. U. und bel $5 \%$ H.Z.; Auflösungskörper: I. Stadium $\{100\} \cdot\{h k 0\}$ Fig. 2, II. Stadium $\{h k 0\}$ Fig. 3 (Photographie eines Krystallkörpers bei 0,5 proz. U.), 1II. Stadium $\{h k 0\} \cdot\{h k h\}$ Fig. 4; Endkörper der Auflösung $\{h k k\}$ Fig. 5.

Fig. 6. Endkörper bei 1 proz. U. und bei $40 \%$ H.z.

Fig. 7. Endkorper bei 1 proz. U. und bei $80 \%$ H.Z.

Fig. 8-10. Endkörper der Auflösung $\{h k k\} \cdot\{110\}$ einer Kombination $\{100\} \cdot\{110\}$.

Fig. 8 bei 0,5 proz. U. und bei $5 \%$ H.Z.

Fig. 9 bei 1 proz. U, und bei $40 \%$ H.Z.

Fig. 10 bei 1 proz. U. und bei $80 \%$ H.Z.

Fig. 11-15. A uflösungskörper und Endkörper der Auflösung einer Kombination $\{100\} \cdot\{111\}$.

Fig. 11 und 12. Auflösungskörper $\{h k k\} \cdot\{111\}$ in 2 wei verschiedenen Stadien bei 0,5 proz. U. und bei $5 \%$ H.Z.

Fig. 13. Endkörper $\{h k k\}$ bei 0,25 proz. U. und bei $5 \%$ H.Z. 
Über die Auflösung von Chlornatriumkrystallen in harnstoff haltigen Lösungen. 331

Fig. 14. Endkörper $\{h k h\}$ bei 1 proz. U. und bei $40 \%$ H.Z.

Fig. 15. Endkörper $\{h k k\}$ bei 1 proz. U. und bei $80 \%$ H.Z. Kugel.

Fig. 16-20. Auflösungskörper und Endkörper der Auflösung einer

Fig. 16. Auflösungskörper bei 0,25 proz. U. und bei $5 \%$ H.Z.

Fig. 17. Endkörper $\{h k h\}$ bei 0,5 proz. U. und bei $5 \%$ II.Z.

Fig. 18. Endkörper bei 1 proz. U. und bei $20 \%$ H.Z.

Fig. 19. Endkörper bei 1 proz. U. und bei $40 \%$ H.Z.

Fig. 20. Endkörper bei 1 proz. U. und bei $80 \%$ H.Z.

Fig. 21. Endkörper der Auflösung $\{110\}$ eines Rhombendodekaëders bei 1 proz. U. und bei $80 \%$ H.Z.

Die Aufnahme der Krystallkörper in natürlicher Größe geschah nach einem von Dr. Wetzel-Kiel angewandten Verfahren in indirektem Licht. (Vgl. 6. Jahresber. d. Niedersächs. geol. Ver. 1913, 28.) Die Lichtquelle beleuchtete ein Gypsparaboloid (mit Lithopone-weiß überstrichen), in dessen Brennpunkt sich das Objekt befand, während das Objektiv des photographischen Apparates hinter dem im Scheitel durchbohrten Paraboloid angebracht war. 